\title{
Campo político-institucional y procesamiento del malestar social en Chile, 1999-2009
}

\section{Political-Institutional field and processing of social unrest: Chile, 1999-2009}

\author{
Carlos Durán Migliardi*
}

\begin{abstract}
Resumen: Este artículo se propone exponer, desde una perspectiva socio-histórica, cuatro hitos representativos de las formas de procesamiento del malestar social generadas por el campo político-institucional chileno durante el período que media entre la elección presidencial del año 1999 y el último año del primer gobierno de Michelle Bachelet (2009): La "retórica cosista" desplegada en la campaña presidencial de 1999, el "acuerdo para la modernización del Estado" con que se resolvió la crisis generada por el "caso MOP-GATE", la conformación del Consejo Asesor Presidencial como respuesta a la "Revolución Pingüina" de 2006 y la activación de la política de "bonos" en el contexto de la crisis económica de 2009. Se concluye con un análisis de los elementos de similitud y diferencia posibles de observar en las estrategias de procesamiento del malestar social observadas.
\end{abstract}

Palabras clave: Historia reciente, Chile, malestar social, campo político-institucional

\begin{abstract}
This article aims to expose, from a socio-historical perspective, four representative landmarks of the forms of processing social unrest generated by the Chilean politicalinstitutional field during the period between the presidential election of 1999 and the last year of the first Michelle Bachelet government (2009). The "retórica cosista" deployed in the 1999 presidential campaign, the "Acuerdo para la modernización del Estado" that the crisis caused by the "caso MOP-GATE" was resolved, the creation of the Consejo asesor presidencial" in response to the "Revolución Pinguina" of 2006 and activation of the policy of "bonos" in the context of the economic crisis of 2009. it concludes with an analysis of the elements of similarity and possible difference observed in processing strategies social unrest observed.
\end{abstract}

Key Words: Recent History, Chile, Social Unrest, Politic-Institutional Field

Recibido: 1 septiembre 2017

Aceptado: 3 noviembre 2017

- Investigador chileno. Doctor en investigación en ciencias sociales. Investigador asociado CEDER Universidad de Los Lagos. Santiago de Chile. Este artículo ha sido elaborado en el marco del proyecto de investigación FONDECYT 11140380 "El campo político-discursivo chileno en un contexto de dislocación. Continuidades y transformaciones", con fondos de CONICYT, Gobierno de Chile.carlos.duran@ulagos.cl 


\section{Introducción}

Uno de los aspectos que le otorgan a la política su especificidad es el de operar como espacio de producción y fijación del sentido de lo social ${ }^{2}$. ¿Cómo trazar la distinción entre los asuntos privados y la vida pública?; ¿Cuáles son los valores que han de operar como principios organizadores de lo social?; ¿cómo interpretar y procesar los malestares sociales que, ineludiblemente, se harán siempre presentes? Frente a estos desafíos, la lógica política actúa como ámbito de resolución, siempre parcial e inestable. En un marco de conflicto, competencia y desigual distribución del poder, se constituye como campo privilegiado de producción de un sentido que permita interpretar y estabilizar el mundo social fijando valores centrales, construyendo identificaciones, estableciendo clivajes y construyendo estrategias discursivas capaces de interpelar a las distintas posiciones que conforman el mundo social. En otras palabras, y tal como lo señalara Norbert Lechner hace décadas atrás, un componente central de la política consiste precisamente en delimitar los alcances, límites y sentidos de la política misma ${ }^{3}$.

Pues bien, en este artículo, nuestro objetivo es precisamente centrar la atención en la forma en que, en el contexto del proceso político chileno reciente, se ha gestado la producción política de sentido frente a situaciones específicas de expresión latente y/o manifiesta del malestar social. Centrando nuestra atención en el campo político hegemónico ${ }^{4}$ conformado en Chile desde el fin de la dictadura militar en el año 1990, exponemos -desde una perspectiva socio-histórica- cuatro hitos representativos de las formas de procesamiento del malestar social durante el período que media entre la elección presidencial de 1999 y el último año del primer gobierno de Michelle Bachelet (2009): La "retórica cosista" desplegada en la campaña presidencial de 1999; el "acuerdo para la modernización del Estado" del año 2003; la conformación del Consejo Asesor Presidencial como respuesta a la "Revolución Pingüina" de 2006 y la activación, por último, de la política de "bonos" en el contexto de la crisis económica de 2009.

Los hitos que abordamos se inscriben en un contexto caracterizado tanto por la consolidación del campo político postransicional como por la emergencia de malestares sociales que, expresados de modo latente o manifiesto, forzaron a la producción de estrategias de procesamiento distintas a las que caracterizaron el contexto socio-político inmediatamente posterior al fin de la dictadura (1990-1999) 5 .

\footnotetext{
${ }^{2}$ Acerca del carácter productor de sentido que asume la política, véase Ernesto Laclau, La Razón populista, Buenos Aires, FCE, 2005.

${ }^{3}$ Norbert Lechner, “¿Responde la democracia a la búsqueda de certidumbre?”, en Los patios interiores de la democracia. Subjetividad y política, FCE, Santiago, 1988.

${ }^{4}$ El concepto de campo político lo utilizamos en concordancia con lo expuesto en Pierre Bourdieu, Campo de poder, campo intelectual, Buenos Aires, Montressor, 2002. Respecto al concepto de hegemonía, véase Ernesto Laclau y Chantal Mouffe, Hegemonía y estrategia socialista. Hacia una radicalización de la democracia, Buenos Aires, FCE, 2004, pp. 177-190.

${ }^{5}$ Cabe señalar que la noción de malestar social la asumimos, en este trabajo, como el conjunto de expresiones de distancia y tensión entre subjetividad y orden social. Dentro del conjunto de estas expresiones, el antagonismo socio-político constituye solo una de sus formas de visibilización, por lo que su vínculo con el
} 
En todos los hitos abordados, el antecedente explicativo de las estrategias desplegadas (una campaña presidencial, un acuerdo gobierno-oposición, la creación de un consejo asesor presidencial con participación ciudadana y una agresiva política fiscal contra-cíclica) es la activación de contingencias críticas frente a las cuales se anticipaba o expresaba la presencia de malestares ciudadanos: la crisis económica y el desgaste de la Coalición gobernante en 1999-2000, el develamiento de casos de corrupción en el aparato público durante los años 2002 y 2003, la intensificación de las protestas estudiantiles durante los primeros meses del gobierno de Bachelet en el año 2006 y la crisis económica mundial cuyos primeros síntomas comenzaron a sentirse hacia finales del año 2008.

¿Qué tienen en común estos cuatro hitos, y cuál es el sentido de su abordaje en este artículo? Junto con ubicarse en el marco temporal que fluctúa entre lo que definiremos como el debilitamiento del dispositivo transicional ${ }^{6}$ (fines de la década de los noventa del siglo pasado) y la crisis del año 2011 (activada por las inéditas movilizaciones sociales protagonizadas central aunque no exclusivamente por el movimiento estudiantil), los hitos abordados en este trabajo coinciden en expresar modalidades de intervención política trascendentes a la lógica propia de dicho dispositivo ${ }^{7}$. Respondiendo a contingencias críticas de naturaleza distinta a las que caracterizaron el proceso político de la primera década posterior al retorno a la democracia, estas modalidades de intervención política presentan como aspectos comunes el de 1) operar por medio de innovaciones que, sin alterar de modo sustantivo las coordenadas de una práctica política esencialmente consociativa y elitista, 2) representaban una modificación de los términos característicos de la forma transicional: nuevos desafíos frente a los cuales el campo político-institucional hegemónico, por consecuencia, respondía a través de estrategias y posiciones que permiten expresar la presencia de un período parcialmente distinto al de la década de los noventa y su característico foco en la agenda de democratización.

malestar social ha de entenderse como puramente contingente, pudiendo existir síntomas de malestar social que no derivan en la expresión de antagonismos socio-políticos.

${ }^{6}$ Para efectos de este trabajo, utilizamos la categoría de dispositivo para hacer referencia a una red de elementos, discursivos y no discursivos, que tienen como común denominador el de cumplir una "función estratégica concreta” (Giorgio Agamben, ¿Qué es un dispositivo?, Sociológica, año 26, número 73, p. 250). Hablamos de "dispositivo transicional", por consecuencia, para hacer referencia al conjunto de elementos que, articulados, configuraron un período específico en la deriva política chilena y que, de acuerdo a lo que sostenemos en este trabajo, asiste a su progresivo agotamiento hacia fines del siglo XX.

${ }^{7}$ La selección de los cuatro hitos abordados en este trabajo emerge de un trabajo de sistematización realizado en el marco de una investigación de mayor alcance, referida a la configuración del campo político discursivo durante el período 1997-2014. Como parte de dicha investigación, se sistematizó un conjunto de fuentes primarias y secundarias que, desde el campo de la sociología, la ciencia política y la historiografía, abordan el período cubierto en este artículo. De la revisión de dichas fuentes se seleccionó un conjunto de hitos relevantes, cuatro de los cuales son abordados en este trabajo, atendiendo a un criterio de diversidad y representatividad. Esto implica, evidentemente, que los cuatro hitos acá abordados no constituyen necesariamente las cuatro contingencias más relevantes del período abordado, sino más bien coyunturas representativas que condensan la forma en que los actores hegemónicos del campo político-institucional (gobierno y oposición) operaron durante el contexto abordado en esta investigación, y que se diferencian de las formas de operación características del período anterior (1990-1999). 


\begin{tabular}{|l|l|l|l|}
\hline \multicolumn{1}{|c|}{ Hito } & \multicolumn{1}{|c|}{ Coyuntura activadora } & \multicolumn{1}{c|}{ Actores claves } & \multicolumn{1}{c|}{ Eje discursivo } \\
\hline Campaña presidencial & Elecciones presidenciales & Oposición & $\begin{array}{l}\text { Cambio en las prioridades } \\
\text { de la élite gobernante. }\end{array}$ \\
\hline $\begin{array}{l}\text { Acuerdo para la } \\
\text { modernización del Estado }\end{array}$ & Crisis de probidad & $\begin{array}{l}\text { Gobierno } \\
\text { oposición }\end{array}$ & $\begin{array}{l}\text { Capacidad de producción } \\
\text { de acuerdos transversales } \\
\text { para la modernización del } \\
\text { Estado. }\end{array}$ \\
\hline $\begin{array}{l}\text { Consejo Asesor } \\
\text { Presidencial }\end{array}$ & Protestas estudiantiles & Gobierno & Gobierno ciudadano. \\
\hline Política de gasto fiscal & Crisis Económica & Gobierno & $\begin{array}{l}\text { Protección social frente a } \\
\text { la crisis económica. }\end{array}$ \\
\hline
\end{tabular}

En definitiva, en este trabajo deseamos exponer la forma en que el campo políticoinstitucional chileno procesó políticamente el malestar social durante el período que media entre el debilitamiento del dispositivo transicional (finales de la década de los noventa) y la emergencia de la crisis socio-política activada a partir del año 2011. Nuestra hipótesis es que, durante este período, el campo político-institucional debió enfrentarse a coyunturas críticas frente a las cuales no bastaban los mecanismos de procesamiento típicos de la década de los noventa, lo que derivó en la producción de estrategias de innovación política que, como se muestra en los cuatro hitos acá observados, forzaron a la modificación parcial de los términos a partir de los cuales se había fundado el así llamado "pacto transicional" que caracterizó el tránsito desde el autoritarismo a la democracia en Chile. ${ }^{8}$

\section{Chile a fin de siglo: agotamiento del dispositivo transicional y nuevos malestares.}

Los años inmediatamente posteriores al fin de la dictadura militar se caracterizaron por la configuración de un escenario político que operó en base a la ecuación entre prudencia, realismo, gradualismo y disposición a la generación de acuerdos entre sus dos actores hegemónicos: la Concertación (que aglutinaba a las fuerzas políticas partícipes de la victoria electoral frente a Pinochet en el plebiscito de 1988) y la Alianza (instancia conformada por las dos principales agrupaciones políticas de la derecha). Eran los tiempos de una "transición" configurada en torno a la centralidad de la normalización democrática, el crecimiento económico y la producción de una difícil gobernabilidad amenazada por la estela autoritaria.

Medido en función de los objetivos de sus actores hegemónicos, el balance de este periodo resultó altamente exitoso. El despliegue de una élite dispuesta a la producción de consensos, con una agenda programática acotada y sometida al imperativo de la estabilidad política y el equilibrio macroeconómico, adicionado a una ciudadanía desmovilizada que adhería más por omisión que por acción a dichas lógicas, había logrado generar un

\footnotetext{
${ }^{8}$ Sobre la caracterización del contexto político aquí abordado en los términos de un "pacto", véase Gregory Weeks and Silvia Borzutzky, "Michelle Bachelet's Government: The Paradoxes of a Chilean President", Journal of Politics in Latin America, $\mathrm{n}^{\circ}$ 3, 2012, 97-121; Claudio Fuentes, El pacto. Poder, constitución y prácticas políticas en Chile (1990-2010), Santiago, Ediciones UDP, 2013.
} 
escenario de reconstrucción progresiva de la institucionalidad democrática. Todo ello, bajo la conducción de una coalición con alta capacidad para administrar el proceso -clausurando fuentes de conflicto, manteniendo su cohesión interna y diluyendo la amenaza de la regresión autoritaria- y de una oposición que, subsidiada por la persistencia de los enclaves autoritarios y un minoritario aunque significativo apoyo ciudadano, cumplía cómodamente su función de veto player. ${ }^{9}$

La fuerte eficiencia de este dispositivo transicional se encuentra fuera de discusión. Más allá de las apreciaciones críticas respecto a los efectos que su despliegue tuvo sobre la configuración del campo político, su relación con el modelo económico-social y su forma de vinculación con la sociedad civil $^{10}$, resulta evidente que sus resultados condujeron a la consolidación de una dinámica política que, de modo contrario a lo que suele ocurrir en contextos de reconstrucción democrática, se caracterizó por sus elevados niveles de estabilidad. Que dicha estabilidad se haya logrado a costa de la exclusión de la ciudadanía $^{11}$, de la sujeción a las bases neoliberales configuradas por la dictadura ${ }^{12}$ o de la consolidación de una democracia "semisoberana" $" 13$ es parte de un debate abierto en el campo de las ciencias sociales y la historiografía, pero sin dudas no excluye la pertinencia de reconocer su efectividad.

Con el correr de los años, sin embargo, este contexto fue variando progresivamente. La exitosa política de los consensos promovida por Aylwin (1990-1994) fue girando hacia el eje de la modernización económico-social durante la administración de su sucesor, Eduardo Frei (1994-2000). Y, con ello, el foco eminentemente político del contexto anterior fue reemplazado por una modalidad de gestión de marcado tono tecnocrático y de una casi indisimulada comodidad con las bases fundamentales del modelo económico heredado de la dictadura. Progresivamente, los temas propios de la transición abrían paso a nuevas agendas vinculadas a la apertura económica, la producción de nuevas políticas públicas y la modernización del Estado, entre otros tópicos. Los "nuevos tiempos" anunciados por el Presidente Frei en su campaña electoral parecían haber llegado, aunque con ellos

\footnotetext{
${ }^{9}$ El concepto de enclaves autoritarios ha sido ampliamente desarrollado en Chile, y alude al conjunto de elementos institucionales, actorales y ético-simbólicos que, heredados del régimen autoritario saliente, persisten en la escena democrática y limitan su expansión. Sobre esto, véase Manuel Antonio Garretón, Hacia una nueva era política. Estudio sobre las democratizaciones, Santiago, FCE, 1995. Respecto al concepto de "veto players", éste refiere a actores políticos minoritarios que, por condiciones contextuales e institucionales, cuentan con una capacidad de veto sobre el sistema político. Sobre ello, véase George Tsebelis, Veto Players: How Political Institutions Work, Princeton University Press, New Yersey, 2002.

${ }^{10}$ Una de las elaboraciones críticas de mayor impacto respecto al dispositivo transicional puede ver expuesta en Tomás Moulian, Chile actual. Anatomía de un mito, Santiago, LOM, 1997. En dicha obra, el sociólogo chileno caracteriza la arquitectura democrática transicional como una "jaula de hierro" (pp 45-56) que bloquea toda posibilidad de despliegue de la deliberación democrática que pueda poner en cuestión los consensos producidos por la élite política hegemónica.

${ }^{11}$ Claudio Fuentes, El pacto. Poder, constitución y prácticas políticas en Chile (1990-2010), op. cit., 17.

12 Manuel Antonio Garretón, Neoliberalismo corregido y progresismo limitado. Los gobiernos de la Concertación en Chile, 1990-2010, Santiago, ARCIS-CLACSO, 2012.

${ }^{13}$ Carlos Hunneus, La democracia semisoberana. Chile después de Pinochet, Santiago, Taurus, 2014.
} 
persistieran los mismos actores y lógicas que caracterizaron la reconfiguración del campo político-institucional durante el gobierno de su predecesor.

Esta situación de equilibrio, sin embargo, comienza a verse alterada a fines de los noventa. Tres eventos acontecidos entre los años 1998 y 1999 marcan, -entre otros procesos de menor visibilidad, la activación de un punto de inflexión en la dinámica política de la época que -como sostendremos más adelante- forzó a los actores político-hegemónicos a activar nuevas estrategias de intervención que pudieran dar respuesta a un escenario para el cual las lógicas propias del dispositivo transicional se volvían progresivamente insuficientes: en primer lugar, la sustantiva baja en los niveles de participación ciudadana manifestada en las elecciones parlamentarias de $1997^{14}$, fenómeno que sintomatizó de modo temprano la producción de un proceso progresivo de desafección y des-ciudadanización electoral que se profundizaría durante los años siguientes; en segundo término, la detención -en agosto de 1998- del en ese entonces Senador Pinochet en Londres, situación que entre sus muchos efectos generó un profundo debilitamiento de la cohesión interna del mundo concertacionista, dividido entre el axioma de la gobernabilidad y la reivindicación de la justicia ${ }^{15}$; y, por último, la activación de una severa contracción económica que, durante 1999, alcanzó las dimensiones de una recesión y puso en riesgo el axioma de la estabilidad macroeconómica y el equilibrio financiero sobre el cual descansaba la legitimidad del modelo económico-social heredado de la dictadura.

Paralelo a estos hechos, el capítulo chileno del Programa de las Naciones Unidas para el Desarrollo Humano publicaba, en los primero meses del año 1998, su segundo Informe de Desarrollo Humano intitulado "Las paradojas de la modernización", el que constataba la presencia larvada de un malestar subjetivo que operaba como escenario de trasfondo de un contexto marcado por el crecimiento económico, la reducción de la pobreza y la gobernabilidad democrática. Del mismo modo, advertía acerca de la inexistencia de respuestas políticas que pudieran hacer frente a lo que era interpretado como un estado de creciente desafección ciudadana. Al perder su capacidad para producir sentido, sostenía el Informe, la política institucional iba abriendo las puertas a la acumulación de un malestar catalogado como "difuso" y "desarticulado" pero que, en el mediano plazo, podía operar

\footnotetext{
${ }^{14}$ En dichas elecciones la abstención, sumando nulos y blancos, alcanzó un porcentaje superior al $30 \%$ del universo de potenciales votantes. Si bien este guarismo no destaca en comparación con los niveles de participación característicos de las democracias consolidadas, para el contexto político de la época evidenció una alteración significativa de los patrones de participación electoral dados en Chile desde el plebiscito de 1988. Sobre el fenómeno de la desafección progresiva del electorado chileno a partir de finales de la década de los noventa, con énfasis en el factor generacional, véase Gonzalo Contreras y Patricio Navia, "Diferencias generacionales en la participación electoral en Chile, 1988-2010”, Revista de ciencia política, XXXIII: 2, 2013, 39-54.

${ }^{15}$ Para una descripción pormenorizada de los eventos que acompañaron la detención del ex dictador Pinochet en Londres, véase Mónica Pérez y Felipe Gerdtzen, Augusto Pinochet. 503 días atrapado en Londres, Santiago, Catalonia, 2016. Acerca de la tensión entre el imperativo de la gobernabilidad y la demanda de justicia al interior del conglomerado concertacionista generada como efecto de este acontecimiento, véase Cecilia Baeza-Rodríguez, "Los discursos públicos sobre la gobernabilidad en Chile como relatos de acción pública: un enfoque cognitivista sobre la importación de las ideas", Nuevo mundo. Mundos nuevos. Disponible en: https://nuevomundo.revues.org/11042.
} 
como fuente para la producción de una "desafiliación afectiva y motivacional que, en un contexto crítico, termina por socavar el orden social". ${ }^{16}$

Al interior de la élite intelectual y política de la Concertación, el agregado de estos eventos fue generando un profundo impacto conducente a la activación de un debate inédito en torno a las proyecciones de su gestión. A las visiones optimistas, que interpretaban el mentado clima de malestar como resultado natural de un estado de cambio social acelerado, se contrapusieron interpretaciones críticas que proponían una modificación de las prácticas y contenidos que definieron el accionar de la Concertación desde su llegada al poder. En lo que ambas visiones - motejadas comunicacionalmente como "autocomplacientes" y "autoflagelantes"- concordaban, empero, era en la necesidad de producir respuestas políticas eficaces frente a un contexto social diagnosticado como distinto al transicional, con la emergencia de nuevas demandas sociales y la instalación de un malestar social aún difícil de procesar. ${ }^{17}$

El fin de siglo, así, ubicaba al campo político chileno frente a nuevos desafíos respecto a los cuales el exitoso dispositivo transicional se manifestaba como insuficiente. Mientras la Concertación se enfrentaba al reto de recrear su identidad en un contexto socio-político distinto al de su origen, a la derecha se le abría la posibilidad de participar de un modo más protagónico en la construcción de la hegemonía discursiva del nuevo período que se abría. Todo ello, bajo un escenario de transfondo constituido por una sociedad que había vivenciado su propia transición, distanciándose progresivamente de los “miedos" a la regresión autoritaria e incorporando en su agenda de demandas nuevos tópicos, anhelos y expectativas.

Hacia fines de la década de los noventa, por consecuencia, comienza a gestarse un contexto sociopolítico que, si bien en lo fundamental operaba bajo los mismos principios que definen el dispositivo transicional arriba descrito, obligaba a sus actores hegemónicos a la innovación y producción de nuevas estrategias de producción de sentido, entre las cuales se cuentan las cuatro coyunturas que en adelante observaremos.

\footnotetext{
16 PNUD, Informe de desarrollo humano en Chile. Las paradojas de la modernización. Santiago, $1998,24$. Cabe consignar que el encuadre teórico del Informe PNUD recoge, en gran medida, las reflexiones generadas desde la década de los ochenta por Norbert Lechner en torno a la reivindicación de la centralidad del vínculo entre política y subjetividad. No es casual, por consecuencia, la relevancia que en este Informe adquirió el concepto de "malestar subjetivo", asumido como un factor clave a la hora de ponderar la capacidad de la política para producir sentidos y cohesión. Sobre este tópico, véase Norbert Lechner, Los patios interiores de la democracia. Subjetividad y política, op. cit.

${ }^{17}$ Entre la extensa bibliografía que trata esta disputa entre "autocomplacientes y autoflagelantes" al interior del mundo concertacionista, puede verse Alfredo Joignant y Amparo Menéndez-Carrión, De la democracia de los acuerdos a los dilemas de la polis: ¿transición incompleta o ciudadanía pendiente?, en La caja de pandora. El retorno de la transición chilena Joignant, Santiago, Planeta/Ariel, 13-48.
} 


\section{Antipolítica y retórica de la eficiencia: la campaña presidencial de la derecha durante las elecciones del año 1999-2000.}

La noche del 30 de mayo de 1999 el optimismo se imponía en las filas concertacionistas. Durante esa jornada se había alcanzado una amplia participación en las inéditas primarias directas y vinculantes organizadas para elegir a su candidato presidencial, lo que fue interpretado como inequívoca muestra del profundo arraigo ciudadano de la Coalición. Pese a las dificultades de los últimos dos años (especialmente en materia económica) y a los fuertes déficits observados en el liderazgo del Presidente Frei ${ }^{18}$, cerca de un millón y medio de chilenos participaba voluntariamente de un acto que daba cuenta de una aparentemente incombustible adhesión a la alianza de gobierno ${ }^{19}$. Para los militantes del ala izquierda de la Concertación, en tanto, el resultado de la primaria era doblemente satisfactorio, toda vez que ratificaba la creciente influencia del "bloque progresista" y consolidaba el liderazgo de su candidato Ricardo Lagos. ${ }^{20}$

Con la candidatura oficialista definida, restaba hacer frente a la exitosa estrategia de posicionamiento mantenida por el candidato opositor y militante de la Unión Demócrata independiente $^{21}$ Joaquín Lavín, quien había logrado un alto posicionamiento público gracias a su mediática gestión edilicia en la acaudalada comuna de Las Condes. ${ }^{22}$ Luego de

\footnotetext{
18 Manuel Antonio Garretón, "La (in)conducción política del segundo gobierno democrático” en "El período del Presidente Frei Ruiz Tagle. Muñoz”, Santiago, Editorial Universitaria, 2003, 52-80.

${ }^{19}$ El porcentaje de participación en este evento rondó el $20 \%$ del universo electoral. Sus resultados le otorgaron una sólida ventaja al candidato Ricardo Lagos quien, con un $71 \%$, se impuso a la opción democratacristiana representada por Andrés Zaldívar.

${ }^{20}$ El liderazgo de Lagos data del contexto del plebiscito de 1988 cuando, en el marco de un debate televisado, sorprendió a la audiencia con una intervención en la que apuntó directamente a Pinochet. Dicha intervención, conocida como "el dedo de Lagos", le valió un amplio nivel de reconocimiento que lo ubicó como referente indiscutido de la centroizquierda chilena. Sobre este acontecimiento, Ricardo Lagos, Mi vida. De la infancia a la lucha contra la dictadura. Memorias I, Santiago, Debate, 2013. Sobre su trayectoria político-intelectual, Marcelo Mella, "El eclecticismo no resuelto del liderazgo de Ricardo Lagos", Documentos y Aportes en Administración Pública y Gestión Estatal, Santiago, 2010, 10: 14, 113-142 y Allan Angell, Elecciones Presidenciales, Democracia y Partidos Políticos en el Chile Post Pinochet, Santiago, Instituto de Historia PUC-Centro de Estudios Bicentenario, Santiago, 2005.

${ }^{21} \mathrm{La}$ UDI es un partido conformado por antiguos colaboradores de la Dictadura provenientes de la tradición "gremialista" surgida a fines de los sesenta. Configurada en torno a una compleja articulación entre liberalismo económico, corporativismo y conservadurismo, logró constituirse en la principal fuerza política del país en las elecciones parlamentarias del año 2001. Para una revisión de su historia, Víctor Muñoz, Historia de la UDI. Generaciones y cultura política (1973-2013), Santiago, Ediciones Universidad Alberto Hurtado, 2016; para la descripción de su período de crecimiento durante los noventa, Alfredo Joignant y Patricio Navia, "De la política de individuos a los hombres de partido", Estudios públicos, 89, Santiago de Chile, 2003, 129-171.

22 Joaquín Lavín es un economista y político que alcanzó notoriedad por su colaboración con la dictadura en materia económica y por su obra "La revolución silenciosa", utilizada como eje comunicacional de la campaña pinochetista en 1988. Retornada la democracia, tuvo una ascendente carrera política fortalecida con su elección como Alcalde en 1992 y su posterior reelección con más del 77\% de los votos en 1996, triunfo que lo instaló como principal liderazgo opositor. Para una descripción de su trayectoria política, Verónica Valdivia, La alcaldía de Joaquín Lavín y el lavinismo político en el Chile de los noventa, Disponible en: www.historiapolitica.com, 2012.
} 
una fase inicial de repliegue, la candidatura laguista comenzó una campaña signada por un tono reformista de combate a la desigualdad y generación de ajustes distributivos al modelo económico-social. Pese a las altas expectativas que en la derecha generaba la candidatura de Lavín, el oficialismo confiaba en que la fortaleza doctrinaria de Lagos terminaría por imponerse a una candidatura que, se asumía, constituía fundamentalmente el resultado de una atractiva pero superficial campaña de marketing político.

Y, sin embargo, el despliegue definitivo de la campaña fue contradiciendo dicho pronóstico. Mientras Lagos mantenía consistentemente su conocido estilo de hombre de Estado, republicano y sobrio, y densificaba el debate público con sus reflexiones y propuestas en torno al imperativo del combate a la desigualdad, Lavín profundizaba el tono de lo que había sido hasta ese momento su performance municipal, recurriendo a frases y propuestas simples en las que afirmaba un conjunto reducido de ideas-fuerza sumariables en 1) su ubicación del lado del malestar ciudadano frente a "las peleas políticas" y la "ineficiencia" gubernamental, 2) su oferta de una administración fundada en la capacidad de gestión, 3) su apelación a "los problemas concretos de la gente" como eje de su plataforma programática y 4) su invocación a la idea del "cambio" como un atributo regular y no traumático de la interacción democrática.

Alterando los términos del debate electoral, Lavín fue conduciendo hábilmente a Lagos hacia un terreno para él desconocido. Frente a las oposiciones propias del clivaje democracia-autoritarismo que configuraron el contexto previo, instalaba la distinción entre una oferta de administración eficiente y cercana a las preocupaciones de "la gente" versus una élite política que "ya ha tenido su oportunidad de ser gobierno" y que "ha perdido capacidad para enfrentar los problemas del país". Lejos de manifestar una disputa entre proyectos antagónicos de sociedad, así, Lavín significaba la contienda presidencial en los términos de una oposición no traumática entre continuidad y cambio en los modos de la gestión gubernamental. "Si uno lee los programas de gobierno -señalaba el candidato-, probablemente no haya tantas diferencias. Para mí, la gran diferencia entre mí programa y el de ellos es que ellos han tenido diez años para hacerlo y no lo han hecho. Yo sí lo voy a hacer". 23

Avalado por su gestión como Alcalde, el "fenómeno Lavín" logró finalmente generar un acelerado desplazamiento en los ejes sobre los cuales se disputó la contienda presidencial. Por medio del despliegue sistemático de una retórica de la "no política" que al mismo

\footnotetext{
23 Esta y las referencias anteriores fueron extraídas del Debate Presidencial del 2 de noviembre 1999, disponible en: https://www.youtube.com/watch?v=xt5XYWAmGFw. (fecha de consulta: 20 de abril 2016). Para una exposición detallada de la dinámica de la campaña electoral de 1999, véase Juan Pablo Sáez, "La estrategia argumentativa de Joaquín Lavín y la construcción de un nuevo ethos discursivo en la política chilena" Comunicación y medios, 20. Disponible en:

http://www.comunicacionymedios.uchile.cl/index.php/RCM/article/view/15017, 2009; Patricio Navia y Alfredo Joignant, Las elecciones presidenciales de 1999: La participación electoral y el nuevo votante chileno, Chile 1999-2000. en Francisco Rojas editor, Nuevo Gobierno: desafíos de la reconciliación, Santiago, FLACSO, 2000; José Velasco, "Nueva imagen electoral en Chile: campañas de Lagos y Lavín”, Revista Latinoamericana de Comunicación, 69, 2000, 28-35.
} 
tiempo no se inhibía en destacar los logros de los gobiernos concertacionistas, Lavín lograba cuestionar la persistencia de la "política tradicional" y ofrecía, como alternativa, una propuesta de cambio fundada en la eficiencia de una administración cuya única guía serían "los problemas concretos de la gente".

De este modo es como, si la campaña de Lagos buscaba traducir el malestar ciudadano hacia un cuestionamiento de algunos de los rasgos del modelo económico-social heredado de la dictadura y la persistencia de los enclaves autoritarios, la retórica lavinista se concentraba exitosamente en destacar la desafección ciudadana frente a una política "alejada de sus preocupaciones":

Cuántas veces me ha tocado asistir a programas de televisión en que, cuando estoy hablando de las formas de enfrentar la delincuencia o la manera de eliminar las levantadas a las 6 de la mañana para sacar un número en un consultorio, viene alguien y pregunta: "bien alcalde, pero volviendo ahora a los grandes temas nacionales ¿qué piensa usted de los senadores designados?” (...) Por dentro me dan ganas de decirle: “¿Cómo que los grandes temas nacionales? ¿Hasta cuándo caemos en la trampa de la política tradicional?" Esa trampa tiende a asociar los grandes temas con los temas políticos. En cambio, las preocupaciones de la vida diaria de los chilenos serían una especie de tema menor. ${ }^{24}$

Un candidato ubicado del lado de "la gente y sus problemas" versus un establishment "insensible" a los malestares ciudadanos constituía una imagen sumamente potente, que ubicaba a la derecha en un lugar distinto al de su condición de mero instrumento para el blindaje del legado autoritario, concentrada ahora en capitalizar el agotamiento de la retórica transicional con su oferta de "gestión eficiente" de un tipo de sociedad que - se preocupaba de repetir insistentemente Lavín- gozaba del consenso extendido de la sociedad chilena, pero cuya potencialidad se veía atrofiada por la ineficiencia gubernamental:

Ellos ya llevan dos gobiernos, ya llevan diez años, ya tuvieron su oportunidad. Llegó la hora de buscar algo distinto, nuevo. Hagamos el cambio $(. .$.$) con un gobierno distinto, con un presidente en acción, en$ terreno, que trabaje con todos y que sin peleas políticas se dedique $100 \%$ a resolver los problemas concretos de los chilenos. Dar más trabajo, combatir a la delincuencia, mejorar la salud, entregar igualdad de oportunidades. Dejemos atrás el pasado" 25

A la luz del resultado de la elección, en la que Lagos obtuvo una estrecha victoria en segunda vuelta luego del virtual empate logrado en la primera, esta fórmula de interpelación constituyó un notable acierto en cuanto a su objetivo de interpelar a una ciudadanía desafectada de su otrora sólida adhesión a la épica concertacionista de la democratización. Pese a ser derrotada, la candidatura lavinista marcó un hito fundamental

\footnotetext{
${ }^{24}$ Citado por Sáez, op. cit., 13.

25 Joaquín Lavín, Franja Electoral segunda vuelta presidencial, 2000. Disponible en: https://www.youtube.com/watch? $\mathrm{v}=8 \mathrm{CgMlobTEeU}$
} 
en la reconfiguración de los clivajes de la transición y en el reposicionamiento -incluso a contrapelo de sus propios deseos- de la derecha como un actor con vocación de mayoría ${ }^{26}$. Pero la eficacia del "alcalde-candidato" no se redujo al reposicionamiento de su sector. Por el contrario, su influencia se extendió al punto de producir un acelerado efecto de "lavinización" del campo político ${ }^{27}$ que, ya desde la segunda vuelta electoral, mostró sus efectos en el redireccionamiento del mensaje concertacionista hacia los ejes temáticos relevados por el candidato del "cambio". ${ }^{28}$ Las elecciones municipales del 2000 y parlamentarias del 2001, posteriormente, terminarían por ratificar no solo el crecimiento y consolidación de la fortaleza de la UDI, sino que además el primado transversal de la retórica "cosista" y tecnocrática desplegada por Lavín. ${ }^{29}$

De este modo es como, mientras la élite concertacionista padecía hacia fines de los noventa de un áspero debate en torno a las luces y sombras de su proyecto, la retórica de "los problemas concretos de la gente" se iba imponiendo con su ágil apelación a la solución tecnocrática de las fuentes del malestar ciudadano. Mientras el agotamiento del dispositivo transicional generaba una crisis del ethos concertacionista, la derecha lavinista fue abriéndose espacio para construir un relato capaz de interpelar a una ciudadanía que, tras casi una década desde el retorno a la democracia, acumulaba nuevos malestares y aspiraciones.

En definitiva, el discurso lavinista contó con la capacidad de resignificar el sentido de lo político hacia una concepción tecnocratizada con fuerte potencia interpelatoria. Su

${ }^{26}$ La influencia del lavinismo en la reconfiguración del clivaje democracia-autoritarismo, sin embargo, pareciera no haberse expresado de modo categórico en el comportamiento electoral de los chilenos, que en lo fundamental votaron en la presidencial del año 1999 en correlación con sus posiciones frente a la dictadura militar. Sin embargo, dicha correlación, expresiva de la persistencia del clivaje democracia-autoritarismo, comenzó a operar bajo nuevos términos (la oposición entre eficiencia/ineficiencia, por ejemplo) y situó a la derecha política en una posición electoralmente ofensiva inédita desde 1990. Para una consideración del perfil de los votantes de Lagos y Lavín en las elecciones de 1999, véase Eugenio Tironi, Felipe Agüero y Eduardo Valenzuela, "Clivajes Políticos En Chile: Perfil Sociológico de Los Electores de Lagos y Lavín.", Perspectivas 5: 11, 2001, 73-87

${ }^{27}$ Sobre esta idea de la "lavinización" del escenario político como efecto del fenómeno electoral reseñado, véase Velasco, op. cit.; Emanuelle Barozet, "Movilización de recursos y redes sociales en los neopopulismos: hipótesis de trabajo para el caso chileno", Revista de ciencia política XXIII: 1, 2003, 39-54.

${ }^{28}$ El sorpresivo empate de la primera vuelta produjo una reformulación tanto del equipo como del foco estratégico de la campaña laguista, lo que derivó en un viraje hacia el electorado centrista y la apropiación de los ejes programáticos de Lavín. Sobre este tópico en particular, véase Ernesto Ottone, El segundo piso. Un ejercicio de memoria, Santiago, Debate, 2016; Patricio Silva, "Estilos políticos y orientación tecnocrática bajo los gobiernos de Lagos y Bachelet”, Revista de sociología, 21, 2007, 79-105; Ominami, Carlos, Secretos de la Concertación. Recuerdos para el futuro, Santiago, La Tercera ediciones, 2011, 193-270.

${ }^{29}$ Utilizado frecuentemente en términos denostativos, el apelativo "cosista" era significado desde el lavinismo como sinónimo de "buena política" y eficiencia. Y es que, tal y como puntualizaba el en ese entonces Director del influyente periódico El Mercurio, "El cosismo es imaginar y llevar adelante fórmulas sociales y económicas que apunten a las necesidades concretas de la gente y que muevan la sensibilidad de ésta. El cosismo supone tanto afán por las cosas, que las distancias partidistas tienden a olvidarse en el trabajo por la comunidad. Por último, el gobierno cosista se hace con la gente, y no sobre ella o contra ella". Citado en Valdivia, op.cit, 28. Sobre la naturaleza transversal de la tecnocratización de la política como resultado del fenómeno Lavín, véase Silva, op. cit. 
relevancia ha de ser vista, en este sentido, no solo en su capacidad para fortalecer el flanco derecho del espacio político hegemónico sino que además, y sobre todo, en su éxito en dotar a todo el campo político de contenidos y estilos discursivos capaces de trascender los límites de la gramática transicional predominante durante toda la década de los noventa.

\section{“Alta política” y modernización: el acuerdo Lagos-Longueira del año 2003.}

El 18 de octubre de 2002, el semanario Qué Pasa publicó una investigación cuyo título -"El escándalo mejor guardado de la Concertación" 30 - llamó inmediatamente la atención de la opinión pública. En él, se presentaban detalles referidos a irregularidades en la emisión de certificados de revisión técnica automotriz en una planta de la ciudad de Rancagua que involucraban a autoridades y parlamentarios adscritos a la alianza de gobierno. Prontamente, los hechos denunciados generaron un efecto "bola de nieve" que terminaría por exponer un conjunto de situaciones -algunas irregulares, otras derechamente delictuales- ilustrativas de la porosa relación dinero-política fraguada tras más de una década del retorno a la democracia, y cuyos protagonistas resultaban ser connotados miembros del mundo concertacionista.

Del caso de las plantas de revisión técnica, la atención judicial se fue ampliando hasta incorporar una arista que abarcaba el corazón mismo de la gestión gubernamental. El "caso coimas" -como fue conocida esta investigación-, fue ligado al así llamado "caso MOPGATE", una investigación dirigida a desentrañar prácticas de triangulación de dineros entre empresas privadas, el Ministerio de Obras Públicas (MOP) y una empresa de consultoría (GATE) cuyo fin supuesto era el financiamiento de campañas políticas y la suplementación salarial a funcionarios públicos por la vía de los así llamados "sobresueldos"31.

Durante enero de 2003, la magnitud de la crisis alcanzó una gravedad inusitada de cara al procesamiento y detención -junto a otros funcionarios- del renunciado Ministro de Obras Públicas, el socialista Carlos Cruz. Obligado a abandonar su estrategia inicial sintetizada en la consigna "caiga quien caiga", el gobierno debió encarar este nuevo escenario manifestando una defensa pública al ex funcionario, complementada con el apoyo y solidaridad ofrecida por los máximos dirigentes del conglomerado oficialista. Paralelo a ello, la Corte Suprema sentenciaba el desafuero y procesamiento de cinco parlamentarios y nombraba un Ministro en visita con dedicación exclusiva al caso. Los medios de comunicación poblaban sus titulares con noticias y profundizaban en las distintas aristas del escándalo. La aprobación pública al gobierno y la figura de Lagos -aunque

\footnotetext{
30 Paulo González y Gloria Faúndez, "El escándalo mejor guardado de la Concertación", en Revista Qué Pasa, 18 de Octubre 2012.

${ }^{31}$ Roberto Schiattino, "Directores renuncian en cadena por doble investigación de sobresueldos: Caso Gate desata efecto dominó en Obras Públicas", El Mercurio, viernes 20 de diciembre, 2012 Disponible en: http://diario.elmercurio.com/detalle/index.asp?id=\{9963881d-8df9-462c-bb8f-844585ef5368; Mario Waissbluth, "La Reforma del Estado en Chile 1990-2005 De la Confrontación al Consenso", Boletín Electrónico, ESADE, Barcelona PUBLIC, 2006. Disponible en: http://documents.mx/documents/reformaestado-chile-1990-2005.html.
} 
moderadamente- se veía afectada, y cundía la alarma por las consecuencias a las que podría conducir este inesperado flanco político-judicial.

A poco más de dos años de iniciado su gobierno, así, el Presidente Lagos debía enfrentar lo que posteriormente sería nominada como la peor crisis de los gobiernos de la Concertación, crisis que en ese entonces se manifestaba como corolario de una administración no exenta de problemas. Y es que, tal y como lo señaláramos anteriormente, al agotamiento natural de la coalición gobernante se adicionaba el fortalecimiento de una derecha energizada por el "fenómeno Lavín", además de una situación económica que complotaba contra las expectativas oficialistas. Todo ello, al punto de que no eran pocos los analistas y dirigentes que anticipaban que la administración Lagos sería la última del ciclo de gobiernos de la Concertación. ${ }^{32} \mathrm{Y}$ sin embargo, la deriva posterior de los eventos encaminó esta crisis por la ruta del despliegue de una estrategia de resolución que expresó no solo la capacidad del campo político en su conjunto para inmunizarse frente a las amenazas, sino que también la fuerte potencia interpelatoria que el accionar de las élites políticas seguía generando en la ciudadanía.

El estado de situación comenzó a cambiar cuando sorpresivamente, el día 16 de enero, el Presidente recibía en el Palacio de Gobierno al -en ese entonces- Presidente de la UDI Pablo Longueira. Bajo un tono de fuerte expectación mediática, el encuentro culminaba con el anuncio de un acuerdo para enfrentar la crisis por medio de la puesta en marcha de un conjunto de iniciativas tendientes a "modernizar la gestión del Estado". 33

¿Qué motivos explican esta disposición del principal partido de oposición a sumarse al esfuerzo de superación de una crisis centrada exclusivamente en el gobierno y sus partidos? Sobre esto, existen diversas interpretaciones, entre las cuales se encuentran la certeza respecto a que la sucesión presidencial correspondería a Joaquín Lavín, los temores respecto al impacto de la crisis sobre la estabilidad económico-social, y la posibilidad de aprovechar la coyuntura para avanzar en un conjunto de reformas afines a los principios ideológicos de la derecha tales como la tecnocratización de la alta dirección pública y el financiamiento empresarial a la política.

Como sea, lo cierto es que este encuentro del 16 de enero marcó un parteaguas en la deriva de la crisis. Tras algunas diferencias entre los partidos de la oposición, algunos de cuyos dirigentes apostaban a un desgaste acelerado del gobierno, se impuso la opción por resolver colaborativamente la crisis. Comenzó así a imponerse un diagnóstico que apuntaba -más

\footnotetext{
${ }^{32}$ Una expresión vívida del ánimo presente en el mundo concertacionista a inicios de la administración Lagos puede verse expuesta en Antonio Cortés Terzi, Gobierno de Lagos: ¿Proyecto histórico o ceremonia del adiós?, Avance, 37, 2000. Disponible en: http://www.socialismo-chileno.org/avance/gobierno-de-lagosproyecto-hist-ricoo-ceremonia-del-adi-s.html.

33 Tres días antes, el en ese entonces Ministro del Interior José Miguel Insulza se había reunido privadamente con Longueira para concordar los términos del encuentro con el Presidente Lagos. Una descripción detallada de la forma en que se gestó este encuentro en Bernarda Arthur, "Histórico compromiso para detener la corrupción", El Mercurio, 31 de enero, 2003. Disponible en: http://diario.elmercurio.com/detalle/index.asp?id=\{6f5bcc59-ff31-4455-8770-a0f36ab2bd0a.
} 
que a la "corrupción" del mundo concertacionista- a la existencia de un Estado afectado por una modernización incompleta, tal y como destacó tempranamente el propio Longueira apenas concluido su encuentro con el Presidente Lagos:

El escenario que hay hoy día es un gran consenso en avanzar en la modernidad. Hay que demostrar y ejercer el liderazgo para salir de esto. Lo peor que nos puede ocurrir es que frente a todos los hechos que estamos conociendo todos los días en los tribunales y medios de comunicación, es que no hagamos del 2003 el año para poder avanzar en la modernidad de Chile. ${ }^{34}$

Hacia idéntica dirección apuntaba una editorial del periódico El Mercurio ${ }^{35}$, según la cual

El encuentro Lagos-Longueira del 16 de enero marcó el antes y el después en la tan anhelada, estudiada y postergada modernización del Estado. Pese a que la crisis política en que se sumió el gobierno por los escándalos de corrupción se mostraba como una ocasión única para avanzar decididamente en esa modernización, las autoridades estaban de tal modo paralizadas que no habían sido capaces de asumir ese desafío. El paso dado por el presidente del gremialismo parece haber sido el antídoto necesario para dejar de lado la catarsis, y asumir con decisión y premura una agenda modernizadora.

A dos semanas de este encuentro, el camino de solución estaba definitivamente trazado. El gobierno presentó lo que vendría a instalarse como la "hoja de ruta" para la superación de la crisis en la forma de una minuta -construida junto a representantes de la oposición- en que se indicaban contenidos y plazos de un total de 49 iniciativas de reforma agrupadas en las áreas de modernización del Estado, Transparencia y Promoción del crecimiento. ${ }^{36}$ En las semanas siguientes, el Congreso trabajó en la aprobación de algunas de estas iniciativas

\footnotetext{
${ }^{34}$ Citado en Mauricio Campusano, "Lagos y Longueira sellan acuerdo para avanzar en modernización del Estado", El Mercurio, 16 de enero, 2003. Disponible en: http://www.emol.com/noticias/nacional/2003/01/16/102567/lagos-y-longueira-sellan-acuerdo-para-avanzaren-modernizacion-del-estado.html.

35 El Mercurio, "Lagos: de la agonía a la dicha. El año en que La Moneda y la Concertación estuvieron en la cuerda floja". Disponible en: http://diario.elmercurio.com/detalle/index.asp?id=\{0873c6cf-9ee2-4807-b20e489758e3defd \}, domingo 28 de diciembre, 2003.

${ }^{36}$ El documento marco acordado por el gobierno y la oposición llevó por nombre el de “Acuerdos políticolegislativos para la modernización del estado, la transparencia y la promoción del crecimiento". La rapidez en la producción de este acuerdo se explica, desde el punto de vista técnico, por la existencia de un considerable acumulado de estudios y propuestas de reforma provenientes del ejecutivo y algunos centros de pensamiento que se encontraban disponibles a ser implementadas. Sobre el contenido y significado de estas reformas, véase Waissbluth, op. cit; Patricio Navia, "Modernización del Estado y Financiamiento de la Política: Una Crisis que se Transformó en Oportunidad. Chile 2003-2004", en Carolina Stefoni editora, Los nuevos escenarios (inter) nacionales, Santiago, FLACSO, 2004. Dada la suma urgencia indicada por el ejecutivo, el paquete de reformas fue discutido y aprobado en una sola jornada llevada a cabo el día 15 de mayo del 2003 , a menos de una semana del Mensaje Presidencial del 21 de mayo. Sobre el contexto y forma de este debate, véase Marjorie Morales, "Nueva Gestión Pública en Chile: Orígenes y efectos", Revista de ciencia política, 34: 2, 2014, 417-438.
} 
-entre las que se encontraban el proyecto de financiamiento a las campañas electorales y la Ley de nuevo Trato laboral- para dejar agendadas aquellas que requerían de un trabajo legislativo más detallado.

Más allá de las especificidades de este paquete de reformas, resulta interesante relevar la forma en que su implementación fue instalada 1) como parte de un esfuerzo que encaraba la ausencia de regulación en el funcionamiento del aparato estatal $\mathrm{y}$, específicamente, en materia de financiamiento a la actividad política y 2) como expresión del espíritu "republicano" y el sentido "de Estado" de una clase dirigente dispuesta a producir acuerdos con miras al interés nacional. Se fue desplegando, de esta forma, una retórica direccionado a destacar el valor de un acuerdo suscrito transversalmente entre dirigentes que asumían como propia la tarea de modernizar el aparato estatal para, de este modo, disminuir la influencia de la discrecionalidad y de los criterios políticos.

Una muestra ejemplar de esta disposición pudo verse observada con ocasión del mensaje ante el Congreso Pleno del 21 de mayo de 2003, instancia en la que el Presidente Lagos dio cuenta de los acuerdos y acciones generadas hasta ese momento. Iniciando con un diagnóstico que destacaba la distancia entre "el Chile que progresa" y el Chile que "no nos gusta (...) un país sumergido en un clima negativo y confuso; un país que parece salpicado de escándalo", Lagos se ocupó de establecer una diferencia categórica entre aquellos casos -minoritarios- de corrupción y aquellas situaciones de irregularidad resultantes de la débil modernización del Estado:

Los problemas que han sucedido en estos últimos meses no son todos iguales. Los hay de corrupción propiamente tal. Otros son resultado de la perversa relación entre dinero y política. Y en la mayoría de los casos son problemas que nacen del atraso de nuestro aparato estatal. Son distintos. Requieren soluciones distintas. No le hace bien a Chile mezclarlos como si se trataran todos de lo mismo. ${ }^{37}$

Hecha esta distinción, el Presidente profundizaba en la valoración de los acuerdos políticos generados en las semanas anteriores a su Mensaje, otorgándoles un sentido republicano que, a su juicio, expresaba la calidad de una élite política con capacidad de generar acuerdos en pos de la gobernabilidad:

Las reformas en marcha no tienen precedentes en nuestra historia reciente. Con ellas estamos dejando atrás problemas del pasado. Cada vez que Chile se ha visto enfrentado a pruebas difíciles, su gente ha sabido siempre ponerse a la altura. Esta es una de esas ocasiones. Juntos estamos haciendo más grande y más digno el futuro de nuestro país y de sus

\footnotetext{
37 Ricardo Lagos, Discurso del Presidente de la República Ricardo lagos Escobar, 21 de mayo 2003. Disponible en: https://www.bcn.cl/historiapolitica/congreso_nacional/discursos/detalle?tipo=presidentes. Fecha de consulta: 03 de mayo 2017. Una profundización en los argumentos gubernamentales utilizados para explicar esta crisis puede verse en Bernardo Navarrete y Giovana Gómez, "La reforma administrativa como reacción a una crisis política. El gobierno de Ricardo Lagos (2000-2006)", Revista de estudios politécnicos, VII, 2009.
} 
instituciones. Por eso reitero y agradezco el aporte de cada uno de ustedes.

De su visión grande acorde con los intereses de la patria. ${ }^{38}$

La gestación de este acuerdo y sus consecuentes medidas tendientes a la modernización del aparato público y del sistema de financiamiento a la actividad política contribuyeron fuertemente a la generación de un punto de inflexión en la administración Lagos. De hecho, en los meses siguientes a la materialización de las acciones contempladas como parte del proceso de modernización acordado, las encuestas comenzaron a mostrar un progresivo repunte en la aprobación presidencial, la que hacia mediados del año 2003 alcanzó niveles superiores al 50\%, para ir creciendo sistemáticamente durante toda la segunda mitad de su mandato. Ocurrió en definitiva que, tal y como sostienen Navia e Izquierdo ${ }^{39}$,

El acuerdo al que llegó el presidente Lagos con el diputado Pablo Longueira $[\ldots]$ fue $[\ldots]$ entendido como una incuestionable señal de gobernabilidad y responsabilidad política por parte del primer mandatario y del líder del principal partido de oposición. Porque Lagos fue capaz de sentarse a negociar con la oposición en un momento particularmente difícil para su gobierno, poniendo por delante los intereses del país sobre los de su propia coalición, la opinión pública aparentemente lo premió con superiores niveles de aprobación.

Pese a la continuidad del accionar judicial y la apertura de nuevas aristas investigativas de alto impacto mediático, lo cierto es que los acuerdos de 2003 lograron redireccionar la agenda política, y permitieron al ejecutivo sortear con éxito su peor crisis y recuperar el amenazado liderazgo presidencial. Pero, además, instalaron a la oposición -y en especial a la UDI- en un registro indiscutido de legitimidad democrática y sentido de Estado que permitió reafirmar sus opciones presidenciales para el año 2006. Una operación, en definitiva, en que los dos actores principales del campo político resultaban vencedores frente a una situación de crisis, logrando de esta forma anteponerse a la eventual emergencia de tendencias centrífugas que pudieran haber erosionado su condición hegemónica.

\section{El "gobierno ciudadano" frente a la "revolución pingüina" de 2006.}

Elevada a un sitial de liderazgo privilegiado gracias a su estilo "ciudadano", su aire renovador y la indiscutible novedad que significaba su condición de mujer, la candidatura de Bachelet en las presidenciales de 2005-6 logró revertir el desgaste de una coalición política que cumplía 16 años en el poder y tres períodos presidenciales consecutivos. Consolidando su condición de "fenómeno político" desde que en 2012 el Presidente Lagos

\footnotetext{
${ }^{38}$ Ricardo Lagos, op. cit., $s / p$. En la misma dirección, Pablo Longueira había señalado días antes del Mensaje Presidencial: "Nunca hemos tramitado un proyecto más trascendental para el país que éste. Debemos sentirnos orgullosos de exhibir una modernización en la Administración Pública, que será un ejemplo en Latinoamérica", citado en Marjorie Morales, op. cit., 423.

39 Patricio Navia y José Izquierdo, "Cambio y continuidad en la elección de Bachelet", América Latina Hoy 46, 2007, 80 .
} 
la nombrara como Ministro de Defensa, la candidata oficialista lograba derrotar cómodamente (con un 53.5\% de los votos) al en ese entonces candidato de Renovación Nacional, el empresario y futuro Presidente Sebastián Piñera, evidenciando de esta forma la extraordinaria capacidad del conglomerado oficialista de apropiarse de la idea del cambio instalada seis años atrás por la fallida candidatura de Lavín. ${ }^{40}$

Las expectativas construidas durante la campaña de Bachelet anticipaban la activación de un nuevo estilo de gobierno, marcado por una impronta ciudadana y alejado de las "viejas prácticas" de una coalición que, a esas alturas del proceso político, había perdido su originaria identificación con la ciudadanía: un gobierno paritario constituido por un gabinete ministerial en el que participaban equitativamente hombres y mujeres, adicionado a la incorporación de nuevos cuadros políticos y técnicos a la gestión gubernamental, constituían señales propias de un liderazgo que asumía como propio el malestar frente a la clase dirigente y la aspiración a una "renovación de la política" que, tal y como señaló la propia Bachelet en su discurso de asunción, lograra reponer su perdida conexión con los ciudadanos: "Este pequeño país [...] hoy quiere dar un gran paso en su historia. Un paso de prosperidad para todos sus hijos, es cierto, pero también una nueva forma de hacer política. Más inclusiva, más participativa, más abierta, más transparente. Una política por y para los ciudadanos". 41

La llegada al gobierno de Bachelet, en definitiva, consolidaba un proceso de modificación del ejercicio del liderazgo político, avizorando la posibilidad de despliegue de un estilo de conducción ciudadano, cercano y refractario respecto a las formas tradicionales de la política, sumando a ello una propuesta programática de consolidación de una política de protección social que lograra hacer frente a la creciente incertidumbre de los chilenos vis a vis un modelo económico-social fundado en la lógica del mercado y el emprendimiento individual. En palabras de Tironi ${ }^{42}$, con Bachelet

Atrás quedaba el liderazgo enfocado en la transformación de las estructuras y la estabilización de las instituciones, preocupado más del juicio de la historia que de los sentimientos de las personas, con un estilo más bien frío, teatral, opaco. Y se abría paso un liderazgo empático, hospitalario, acogedor, que atendía la vulnerabilidad de las personas y elevaba la autoestima de los ciudadanos, más volcado a lo doméstico que a lo utópico.

Y, sin embargo, las promisorias expectativas generadas en torno a Bachelet habrían de durar muy poco. A poco más de un mes del inicio de su mandato, una protesta estudiantil

\footnotetext{
${ }^{40}$ Sobre el significado político del triunfo de Bachelet en las elecciones de 2005-06, véase Mauricio Morales, "La primera mujer Presidenta de Chile. ¿Qué explicó el triunfo de Michelle Bachelet en las elecciones de 2005-2006", Latin American Research Review, 43: 1, 2008, 7-31; Susan Franceschet, "El triunfo de Bachelet y el ascenso político de las mujeres", Nueva sociedad, 202, 2006, 13-22.

${ }^{41}$ Bachelet, Michelle, "Discurso de la Presidenta Michelle Bachelet", 11 de marzo 2006. Disponible en: http://www.archivochile.com/Chile_actual/Elecciones_2005/Bachelet/11_03_2006.pdf.

42 Tironi, Eugenio, Radiografía de una derrota. O cómo Chile cambió sin que la Concertación se diera cuenta, Uqbar, Santiago, 2010, 68.
} 
logra convocar a varios miles de estudiantes secundarios por la tardanza en la entrega del pase escolar. Rápidamente, a esta demanda se fueron sumando otras reivindicaciones que apuntaban al corazón mismo de la matriz neoliberal de la educación chilena, generando una movilización inédita no solo en cuanto a su masividad sino que además en lo que refiere a su impacto mediático y los repertorios de movilización desplegados por los estudiantes durante las varias semanas en que se extendieron sus protestas. Era la "Revolución Pingüina", fenómeno de movilización social más intenso desde el retorno a la democracia, y uno de los antecedentes de los que, cinco años después, sería la irrupción del movimiento por la gratuidad en la educación ${ }^{43}$

Con el correr de las semanas, la intensidad de las movilizaciones fue en aumento, recibiendo como respuesta gubernamental una ambigua solidaridad y "comprensión" combinada con el categórico cuestionamiento a sus formas -marcadas por fuertes dosis de violencia y desorden callejero-, en un intento por apuntalar la autoridad presidencial desde el inicio y subrayar la imagen de un gobierno serio que no alteraba su hoja de ruta por temor al descontento social.

Así las cosas, y ante la fuerte expectativa de un pronunciamiento presidencial -con ocasión del Mensaje al Congreso Pleno del 21 de mayo- que pudiera encaminar las movilizaciones hacia una salida, la primera mandataria elaboró un discurso en el cual la exclusiva referencia al contexto de protestas estudiantiles era desde el locus de defensa del orden público y condena a los actos de violencia estudiantil:

Quiero ciudadanos críticos, conscientes, que planteen sus ideas y sus reivindicaciones. Pero esa crítica debe hacerse con un espíritu constructivo, con propuestas sobre la mesa y, lo más importante, a cara descubierta y sin violencia. Quiero ser muy clara: lo que hemos visto en semanas recientes es inaceptable. ¡No toleraré el vandalismo, ni los destrozos, ni la intimidación a las personas! Aplicaré todo el rigor de la ley. La democracia la ganamos con la cara descubierta y debemos continuar con la cara descubierta ${ }^{44}$.

La opción por el orden público como argumento para encarar las movilizaciones estudiantiles estuvo lejos de dar frutos. Por el contrario, resultó ineficaz tanto en su objetivo de contener las manifestaciones como en la búsqueda por generar un animus favorable en la

\footnotetext{
43 Respecto a las causas que explican el surgimiento de esta movilización estudiantil en el contexto de instalación del gobierno de Bachelet, especial relevancia se le otorga a una modificación en la estructura de oportunidades políticas generada por la retórica ciudadana y participativa de la Presidenta Bachelet durante su campaña electoral, lo que habría generado estímulos para la activación de las movilizaciones sociales en general, y estudiantiles en particular. El desarrollo de este argumento, al igual como una descripción analítica del fenómeno de la "revolución pingüina" puede verse expuesto en Sofía Donoso, "Dynamics of Change in Chile: Explaining the Emergence of the 2006 Pingüino Movement", Journal of Latin American Studies, 45: 1, 2013, 1-29.

44 Michelle Bachelet, Mensaje presidencial 21 de mayo, 2006, s/p. Disponible en: http://www.bcn.cl/historiapolitica/mensajes_presidenciales.
} 
opinión pública, produciendo un efecto de multiplicación de las movilizaciones y de las ocupaciones de establecimientos educacionales.

De este modo es como, presionados por un ultimátum dado por los estudiantes, el gobierno decidió finalmente encarar desde la propia presidencia este conflicto. El día 1 de junio, en Cadena Nacional, la Presidenta Bachelet anunciaba un paquete de medidas entre las cuales destacó la modificación de la Ley Orgánica de Enseñanza, una de las demandas más sentidas por el movimiento estudiantil. Y, acompañado de dichas medidas, convocaba a la conformación de un Consejo Asesor Presidencial dado a la tarea de producir acuerdos en torno a lo que se anticipaba como una "necesaria reforma" del sistema educacional chileno ${ }^{45}$.

Aunque inicialmente contempladas para las áreas de previsión e infancia en el programa de gobierno de Bachelet, la propuesta de conformación de un Consejo Asesor no constituía una novedad. Concordante con su perfil ciudadano y su insistente reconocimiento de una situación de déficit del sistema de representación política, su implementación buscaba amplificar la acotada relevancia que estas comisiones habían alcanzado a lo largo de los gobiernos de la Concertación y relevar su sentido participativo. Y es que, a diferencia de lo ocurrido con las experiencias previas, se trataba en este caso de acentuar la presencia de representantes de sectores y sensibilidades sociales que pudieran compensar el tradicional predominio de funcionarios estatales, representantes de organizaciones políticas y expertos con que se habían conformado históricamente las comisiones asesoras desde el retorno de la democracia. Y ello, además, en un marco contextual de conflicto y movilización social, situación que dotaba a la puesta en marcha de dicha comisión de un sentido notoriamente distinto al de sus predecesoras. ${ }^{46}$

Durante los días inmediatamente posteriores al anuncio del Consejo, y antes del nombramiento de sus participantes, el movimiento estudiantil ingresó en una etapa de fuertes tensiones internas generadas por las distintas posiciones en torno a su participación en esta instancia y el porcentaje de representantes de organizaciones sociales a exigirle al gobierno, lo que derivó finalmente en la opción por interrumpir las movilizaciones y participar de dicha comisión, cuyas sesiones ordinarias comenzaron el mismo mes de junio y se extendieron por un total de 27 semanas. $^{47}$

45 Detalles sobre la deriva del conflicto acá referido pueden verse expuestos en Raúl Henríquez, "El movimiento estudiantil secundario chileno de mayo-junio de 2006: la actuación del poder gubernativo desde una visión macropolítica de la educación”, EDUCERE, 11: 37, 2007, 271-281.

${ }^{46}$ Respecto al sentido de las comisiones asesoras bajos los gobiernos de la Concertación, y la especificidad de la Comisión en materia educacional, véase Carolina Aguilera, "Participación ciudadana en el gobierno de Bachelet: consejos asesores presidenciales", América Latina Hoy, 46, 2007, 119-143; Herwin Cleuren, "Local Democracy and Participation in Post-Authoritarian Chile", European Review of Latin American and Caribbean Studies, 83, 2007.

${ }^{47}$ De los 81 miembros del Consejo, el 17\% (12 en total) correspondió a representantes de las organizaciones en conflicto, distribuidos equitativamente entre universitarios y secundarios. Sobre las disputas internas del movimiento estudiantil frente a la conformación de esta Comisión, véase Jorge Cárcamo, Codificación Política de la Demanda Estudiantil-Secundaria durante la Administración Gubernamental de Michelle Bachelet (2006-2010), Tesis para optar al grado académico de Magister en Análisis sistémico aplicado a la 
En el marco de su funcionamiento, y cumpliendo el mandato presidencial, el Consejo elaboró dos documentos resultantes del trabajo de sus comisiones: un informe preliminar destinado a la elaboración de un diagnóstico del estado del sistema educacional chileno, y un Informe final con observaciones y recomendaciones para una reforma educacional integral que, a falta de acuerdo entre sus miembros, se elaboró como un agregado de recomendaciones y criterios, algunos de los cuales resultaban fuertemente contradictorios entre sí. ${ }^{48}$

Ahora bien, y con independencia de los resultados en cuanto a la generación de insumos para la gestación de la reforma educacional implementada finalmente por Bachelet en 2007 con el concurso unánime del establishment político, es destacable señalar que, en lo que refiere a la desactivación de la protesta social y el encausamiento institucional del debate en torno al tópico educacional, la convocatoria y puesta en funciones del CAP resultó un acierto. Aun considerando los altos costos en términos de adhesión ciudadana pagados por la administración Bachelet como resultado del conflicto, la conformación de esta instancia permitió debilitar las movilizaciones estudiantiles, volver a controlar la agenda pública y, al mismo tiempo, desplazar el debate educativo educativa desde la calle a la institucionalidad. En definitiva, la forma en que el gobierno de Bachelet gestionó la "Revolución Pingüina" por medio de la conformación del CAP en materia educacional representó una manifestación -parcial, acotada y en último término fallida- de las aspiraciones que conformaban la idea del "gobierno ciudadano" desplegada en el marco de su campaña presidencial. Con dicho conflicto, las expectativas cifradas en torno a una nueva forma en el ejercicio del liderazgo ciudadano se pusieron a prueba, materializándose en la conformación de una instancia altamente eficiente en su capacidad para institucionalizar el conflicto, pero deficitaria en cuanto a su deriva posterior, materializada en el posterior diseño y aprobación de una reforma educacional que, en su forma y contenido, respondió a la tradicional lógica de producción de acuerdos político-parlamentarios.

\section{La crisis económica como oportunidad política: Bachelet y la protección social, 2009.}

La relación entre adhesión política, percepciones y desempeño económico ha sido un asunto de primera relevancia a la hora de dar cuenta de los factores que determinan el éxito o fracaso de los gobiernos. Razones y evidencias para determinar una relación entre desempeño económico negativo y pérdida de apoyo ciudadano a los gobiernos existen en abundancia, como también los ejemplos de situaciones en las que dicha relación no ha sido posible verificar o, incluso se ha dado de modo reverso. Con todo, lo cierto es que el así

sociedad, Facultad de ciencias sociales, Universidad de Chile, 2014 . Disponible en http://repositorio.uchile.cl/handle/2250/135905.

${ }^{48}$ Jorge Cárcamo, op. cit. 
llamado "voto económico"49 constituye uno de los centros del interés por explicar la forma en que los ciudadanos y electores configuran sus preferencias y decisiones electorales.

Ahora bien, el caso del inédito aumento de la adhesión a la figura presidencial de Bachelet y su gobierno durante el año 2009 constituye una clara expresión de una contingencia en la que, pese al contexto de crisis económica global que se tradujo en un decrecimiento del $1.5 \%$ del PIB, la primera mandataria logró alcanzar cifras de aprobación nunca antes vistas en la historia democrática del Chile post-dictatorial ${ }^{50}$. De modo contrario al profundo impacto que una década atrás tuvo la crisis económica sobre la adhesión al gobierno del Presidente Frei, así, la crisis económica mundial de los años 2008-2009 constituyó para Bachelet una oportunidad no solo para aumentar sus niveles de adhesión, sino que también, para incorporar a su legado uno de los ejes discursivos fundamentales de su programa de gobierno: la "protección social".

¿De qué forma se gestó esta aparente anomalía en la que una situación de crisis económica se correlaciona positivamente con un incremento en la adhesión y valoración ciudadana a un gobierno?; ¿Qué factores permiten comprender la forma en que un gobierno encuentra, en un contexto recesivo, la oportunidad para consolidar su legado político y superar su discreto desempeño previo?

Durante la campaña electoral que la condujo a la presidencia, uno de los ejes centrales del discurso de Bachelet -junto a la del "gobierno ciudadano"- fue el de la protección social, entendida como el conjunto de acciones generadas desde el Estado para aminorar el riesgo y la incertidumbre a la que se ven afectados aquellos sectores menos aventajados de la sociedad. Pensada como un mecanismo central para el combate de los efectos desintegradores de la desigualdad económica, la protección social asumía en el relato bacheletista la forma de una reivindicación de la función del Estado, postergada tras décadas de predominio de la ideología del libre mercado y la iniciativa individual. Una función que, en el contexto de una economía global tensionada por las fluctuaciones y la contingencia, debía adquirir una centralidad sustancialmente mayor a la generada hasta entonces:

Hemos buscado corregir el modelo de crecimiento, humanizarlo y aminorar la incertidumbre que conlleva, procurando un mejor equilibrio entre expansión económica y equidad social. Más allá de los avances, que son evidentes para cualquiera, la tarea está aún incompleta. A medida que hemos seguido profundizando la plena integración de Chile al mundo, más fuerte se ha hecho la urgencia de reducir las desigualdades y

\footnotetext{
${ }^{49}$ Sobre la categoría voto económico, véase José Sáez, "La función del voto económico. El caso de España”, El trimestre económico, 69: 276, 2002, 475-512.

${ }^{50}$ Según datos recogidos de los estudios de opinión del Centro de Estudios Públicos, durante el momento más álgido de la crisis económica del año 2009 el Presidente Frei alcanzó niveles de adhesión inferiores al 30\%, los más bajos desde 1990. Contrariamente a ello, bajo el telón de fondo de la crisis económica Bachelet aumentó sus niveles de adhesión desde un 39\% (junio 2008) a un 78\% (octubre 2009).
} 
resguardar - a través de una red de protección social- a nuestra gente y nuestra economía de los shocks que afectan la economía internacional. ${ }^{51}$

El foco en la protección social expresaba, en definitiva, un esfuerzo de conformación de un renovado sentido histórico para el bloque concertacionista. Como corolario de reflexiones y estudios desarrollados por la élite intelectual y gubernamental de la Concertación ${ }^{52}$ desde inicios de la década del 2000, la candidatura bacheletista lograba incorporar una línea de continuidad entre el sentido originario de la Coalición - combatir el miedo a la dictadura- y sus nuevos desafíos en un contexto de modernización acelerada -combatir los riesgos sociales-.

Sin embargo, y debido a una multiplicidad de factores vinculados a fenómenos contingentes tales como la ya referida "revolución pingüina" del año 2006, la crisis generada por la fallida implementación del nuevo sistema de transporte metropolitano Transantiago- durante 2007, el estallido de diversos escándalos de irregularidades y corrupción estatal y los múltiples problemas de conducción al interior del ejecutivo y de su coalición política ${ }^{53}$, el relato gubernamental de la protección social no había logrado materializarse en políticas y acciones que lograran un perfilamiento de la administración Bachelet. Lejos de ello, ésta parecía operar inorgánicamente en respuesta a situaciones contingentes que impedían el despliegue de un sentido y un relato unificados en torno a los objetivos de su mandato.

Los tres primeros años de Bachelet en el gobierno, por consecuencia, transcurrieron en un marco de debilidad programática, opacidad discursiva y respuesta a la contingencia. No eran pocos, por consecuencia, los analistas y actores políticos que sentenciaban anticipadamente el destino de su gobierno. Desde la academia, por ejemplo, abundaban las evaluaciones que colocaban el acento en la mala gestión gubernamental y en su déficit discursivo, en la línea de lo manifestado, por ejemplo, en la siguiente reflexión:

La mala gestión del gobierno, la percepción de un aumento de la corrupción y la escalada de protestas durante la administración socialista de la Presidenta Michelle Bachelet han dado lugar a un aumento de críticas hacia la Concertación, coalición que ha gobernado Chile desde el retorno a la democracia en 1990. Algunos han culpado el estilo de liderazgo de Bachelet, mientras que otros han vinculado los problemas de su gobierno más claramente con la propia Concertación. Habitualmente,

51 Michelle Bachelet, Programa de Gobierno Michelle Bachelet 2006-2010, 10. Disponible en: http://www.bcn.cl/obtienearchivo?id=documentos/10221.1/13433/1/2005_programa-MB.pdf.

${ }^{52}$ Los pilares de la política de protección social impulsada por Bachelet en su gobierno pueden ser observados en: MIDEPLAN, Componentes Centrales de un Sistema de Protección Social Sustentable: El Nuevo Escenario Social en Chile, 2005. disponible es http://www.ministeriodesarrollosocial.gob.cl/admin/docdescargas/centrodoc/centrodoc_241.pdf;

Dagmar Raczynski, Sistema Chile Solidario y la Política de Protección Social de Chile. Lecciones del pasado y agenda para el futuro, Santiago, CEPAL, 2008.

${ }^{53}$ Sobre ello, véase Robert Funk, “Chile: segundo tiempo”, Revista de ciencia política, 29: 2, 2003, $301-326$. 
académicos y los medios de comunicación han relacionado los problemas de la coalición a una "ideología de gobiernismo", aludiendo a que la Concertación se encuentra "agotada" o sugiriendo que el gobierno sufre de una "fatiga de material", "desgaste", todo lo cual puede ser señal del "fin de ciclo" de los gobiernos de la Concertación. Estas críticas se centran principalmente en la noción de que la Concertación se ha quedado sin ideas porque ha permanecido demasiado tiempo en el poder ${ }^{54}$.

Desde la derecha política se desplegaba un diagnóstico similar. El líder histórico de Renovación Nacional Andrés Allamand señalaba en este sentido, refiriéndose a la coalición gobernante:

Están atrapados en su propia ambigüedad (...) La presidenta, en su fuero interno, no sabe si quiere administrar, impulsar, corregir, cambiar o derechamente revertir el proyecto de desarrollo del país. Por esta razón, todas sus definiciones respecto a su propio gobierno han sido, hasta ahora, más de forma que de fondo: un gobierno ciudadano, la paridad de género, la renovación de los equipos dirigentes son todas definiciones importantes, pero son más instrumentales que sustantivas (...) El gobierno anda mal porque, además de evidentes problemas de manejo y un ostensible debilitamiento del sentido de autoridad presidencial, no resuelve la forma en que encaja su gestión con el actual proyecto de desarrollo ${ }^{55}$.

Tales eran los balances públicos respecto a la deriva de la Concertación y el gobierno de Bachelet que predominaban a mediados de su gobierno. Hacia finales de 2008, sin embargo, el escenario político cambió abruptamente. A nivel internacional, los síntomas que anticipaban una crisis económica de gran escala ya eran una realidad, y la economía internacional enfrentaba una coyuntura critica de gran magnitud generada centralmente por la alta volatilidad de los flujos financieros y su interconexión global ${ }^{56}$.

La ecuación entre crisis económica, una popularidad presidencial mediocre, un gobierno mal evaluado y la persistencia de conflictos internos en el conglomerado gubernamental permitían anticipar, así, una caída libre del gobierno durante el siguiente año en que, por lo demás, correspondería realizar elecciones presidenciales y parlamentarias. Y sin embargo, esta coyuntura de crisis económica terminó por presentarse para la administración Bachelet no solo como una amenaza sino que al mismo tiempo como una oportunidad de reponer la centralidad del discurso de la protección social, cuestión que sería la que finalmente terminaría por desplegarse durante el año 2009.

La modificación de los ejes discursivos de la administración concertacionista se sucedió de modo rápido. Durante noviembre de 2008 -en el marco de un consejo de gabinete en el que

\footnotetext{
${ }^{54}$ Peter Siavelis, "Enclaves de la transición y democracia chilena", Revista de Ciencia Política, 29: 1, $2009,4$.

55 Andrés Allamand, El desalojo. Por qué la Concertación debe irse el 2010, Santiago, Editorial Aguilar, 2007. 64-65.

56 Sobre la naturaleza de la crisis y su impacto sobre las economías latinoamericanas, véase Ricardo FrenchDavis, "El impacto de la crisis global en América Latina”, Nueva sociedad, 224, 2009, 67-85.
} 
se trató el agravamiento de la crisis económica global $^{57}$ - el equipo político y económico del gobierno decidió la puesta en marcha de una política anticíclica de expansión del gasto fiscal como estrategia para el amortiguamiento de las previsibles consecuencias del entorno internacional sobre la economía nacional ${ }^{58}$. Lo que hasta entonces había sido una continua política amarrada a la ley del equilibrio fiscal, el control de la inflación y la mantención de una retórica de seriedad presupuestaria, giró de este modo hacia un conjunto de anuncios de expansión del gasto en un porcentaje calculado en un $2.8 \%$ del PIB, el que se destinó mayoritariamente a la activación de un sistema de transferencias monetarias directas a más de 3 millones y medio de personas cuyo propósito doble era impulsar la reactivación económica y aminorar el impacto de la recesión económica en los sectores más desfavorecidos.

De este modo es como, a inicios del año 2009 y luego de un acelerado trámite legislativo, la Presidenta Bachelet presentó al Congreso el proyecto de Ley "(que) establece incentivos tributarios transitorios, concede un bono extraordinario para las familias de menores ingresos y, establece otras medidas de apoyo a la inversión y al empleo". En su Mensaje de presentación al Congreso de esta iniciativa, Bachelet inscribía el proyecto como parte de un sello gubernamental centrado en la protección social y la responsabilidad fiscal: "sostuvimos que usaríamos todas las herramientas disponibles para proteger a las personas de esta crisis internacional, y así lo haremos. Supimos ser firmes y prudentes e hicimos lo mismo que hacen muchas jefas de hogar en Chile: ahorramos para un año difícil". ${ }^{5}$

Como era previsible, la discusión de estas iniciativas fue fluida. Unánimemente, la totalidad del Congreso aprobó la iniciativa, destacándose en este sentido el entusiasta apoyo de los parlamentarios opositores, uno de cuyos miembros -el diputado UDI Julio Dittborndeclaraba:

El gasto público que implican estas medidas que hoy estamos analizando, en lugar de desarrollarse a través de los ministerios y de la burocracia estatal, a nuestro juicio, tiene el mérito de apoyar directamente a las familias, por una parte, y a las pequeñas y medianas empresas, por otra.

\footnotetext{
${ }^{57}$ Patricia Politzer, Bachelet en tierra de hombres, Santiago, Editorial Debate, 2010, 244-258.

${ }^{58}$ La operativización de este plan estuvo a cargo del Ministro de Hacienda Andrés Velasco, quien durante gran parte de su gestión había resistido las presiones de amplios sectores de la coalición de gobierno y del propio gabinete presidencial que apostaban al despliegue de una política expansiva que incorporara reformas en ámbitos como el laboral, además de un incremento sustantivo del gasto fiscal, aprovechando los -por aquel entonces- altos precios que alcanzaba el cobre en el mercado internacional que luego, con la activación de la crisis, se desplomaron rápidamente. Las críticas al carácter restrictivo de la política fiscal, así, fueron girando hacia múltiples loas a la capacidad del gobierno - y en especial de su Ministro de Hacienda- de prever la crisis y aprovechar el alza transitoria en los precios del cobre como instrumento de generación de un ahorro fiscal que ahora, en tiempos de crisis, podía ser utilizado.

${ }_{59}$ Michelle Bachelet, "Mensaje de s.e. la presidenta de la República con el que inicia un proyecto de ley que establece incentivos tributarios transitorios, concede un bono extraordinario para las familias de menores ingresos y establece otras medidas de apoyo a la inversión y al empleo", Disponible en http://www.bcn.cl/actualidad_legislativa/plan-economico-crisis-internacional/crisis-economica, 7 de enero 2009.
} 
Es lo que denominamos "beneficio a la vena", que llegará directamente a las personas que se quiere favorecer, que incentivará el gasto $\mathrm{y}$, por lo tanto, contribuirá a que, ojalá, el PIB de este año crezca un poco ${ }^{60}$.

Materializadas a partir del mes de marzo de 2009 -y reeditadas en julio del mismo año-, este despliegue de transferencias monetarias en el contexto de la mayor crisis económica global de las últimas décadas permitió materializar el sentido del discurso de la protección social. Si bien es cierto que meses antes Bachelet había logrado promulgar una reforma previsional que conformaba un "pilar solidario", elevando las pensiones de los grupos más desaventajados, fueron estas políticas de transferencia las que -junto al conjunto de medidas activadas por su gobierno en el contexto de la crisis- lograron consolidar la promesa originaria de un Estado protector y activo frente al riesgo y la incertidumbre económica.

Si bien las elecciones presidenciales de finales del año 2009 condujeron al fin del ciclo de gobiernos concertacionistas, el contexto de crisis económica vivido en el país desde finales del año 2008 no activó situaciones de descontento social ni generó una crisis en la administración gubernamental. Lejos de ello, fue un período en el que la adhesión al gobierno y a la figura de Bachelet se incrementó a niveles históricos, y en el que el relato de la protección social quedó instalado como el sello de su legado presidencial. El sino que vincula crisis económica y crisis política, así, logró ser sorteado exitosamente, convirtiendo una contingencia altamente sensible en una oportunidad para consolidad no solo un liderazgo personal, sino que también una forma de administración y gestión que alcanzó altos niveles de valoración pública.

\section{Conclusiones}

La eficacia de la política institucional es posible de ser evaluada, en gran medida, en función de la capacidad que manifieste para disolver fuentes potenciales de antagonismo, procesar el malestar social y construir soluciones discursivas a los desafíos que la contingencia le presenta. De acuerdo a las condiciones contextuales, ésta irá respondiendo de modos distintos a su desafío principal, consistente en producir sentidos compartidos y hacer frente a las siempre presentes tendencias dislocatorias de lo social.

Ahora bien, y ya situados en el contexto chileno, existe un extendido acuerdo -referido en este artículo- en el campo investigativo de las ciencias sociales y de la historiografía en caracterizar su campo político-institucional como un espacio configurado por un conjunto de características derivadas de la naturaleza de su proceso de recuperación democrática. Lo que en este trabajo hemos denominado como el dispositivo transicional, así, se habría extendido desde la restauración democrática en 1990 hasta, por lo menos, la crisis socio-

${ }_{60}$ Julio Dittborn, Cámara de Diputados República de Chile, Legislatura 356a sesión 121 a 8 enero 2009. Disponible en: http://www.ben.cl/laborparlamentaria/wsgi/consulta/verDiarioDeSesion.py?id=640987. 
política del año 2011: la conjugación entre gradualismo, realismo político, consociativismo y adhesión al modelo económico-social gestado en dictadura habría sido, en este sentido, un componente central de la interacción política generada en Chile durante dos décadas, y constituiría el mecanismo principal para el tratamiento de demandas, el procesamiento del malestar social y la neutralización del antagonismo socio-político.

En este artículo, nos hemos concentrado en un período específico (1999-2009) de la historia política reciente de Chile para observar de qué modo los agentes hegemónicos del campo político-institucional respondieron a una serie de coyunturas críticas. La pregunta de trasfondo giraba en torno a la forma en que el dispositivo transicional se encontraba presente en dichas respuestas. En otras palabras, buscábamos ponderar la persistencia o ruptura del dispositivo transicional en un contexto que, tal y como lo señaláramos, comenzaba a distanciarse de las condiciones que definieron el escenario político chileno durante la década inmediatamente posterior al fin de la dictadura.

En una primera mirada, la variedad de las coyunturas críticas abordadas en este artículo desafección ciudadana frente a la gestión gubernamental, escándalos de corrupción, movilizaciones sociales y crisis económica-, así, no fueron impedimento para la persistencia del dispositivo transicional. Así es como, si el "cosismo" lavinista -extendido luego al conjunto de la élite política- tecnocratizó el lenguaje político para responder a la desafección ciudadana, el acuerdo inter-élite fue el camino de solución a una crisis institucional que daba cuenta de un severo problema en la relación política-dinero. Si frente a las movilizaciones estudiantiles el gobierno de Bachelet respondió con la instalación de una Comisión eficaz en desactivar el conflicto, pero infértil en proponer nuevas políticas públicas que relevaran la crisis del sistema educacional, la respuesta a la crisis del año 2008-9 omitió el debate sobre el modelo de desarrollo y la desigual distribución de la riqueza en Chile.

Sin embargo, esta persistencia de las lógicas de interacción política emergidas del contexto transicional operó en el marco de una modificación, a nuestro juicio relevante, no solo del marco contextual en el que éstas operaron, sino que también de la naturaleza de los desafíos a enfrentar. Y es que, si observamos el período precedente (1990-1998), es fácilmente constatable que gran parte de las coyunturas críticas e hitos que coparon la escena pública durante dicho período se encontraban asociadas a la agenda re-democratizadora y a los desafíos de superación de la herencia autoritaria. Solo por mencionar algunos de esos hitos, recordemos el debate en torno a las reformas laboral y tributaria generadas a inicios del gobierno de Aylwin; la agenda de esclarecimiento de la verdad en materia de violación de los derechos humanos cuyo hito principal podemos situarlo en la creación de la así llamada Comisión Rettig; el enfrentamiento al problema de la violencia política ilustrada en situaciones tales como el crimen del Senador Jaime Guzmán y el secuestro del empresario Cristian Edwards; el procesamiento y condena del jefe de los organismos represivos, el general Manuel Contreras; la crisis política ocasionada con motivo de la detención del ex 
dictador Pinochet en Londres o, por último, la agenda de normalización en el campo de las relaciones internacionales.

Los hitos abordados en este artículo, por el contrario, responden a fenómenos y contingencias que alteran a nuestro juicio de modo sustantivo la agenda arriba ilustrada, abriendo paso a un proceso lento y sostenido de desvanecimiento de un dispositivo transicional que, si bien persistente, comenzaba ya en ese entonces a evidenciar muestras evidentes de descomposición y de insuficiente capacidad para hacer frente a nuevas condiciones den entorno sociopolítico.

Es así como, en primer lugar, la irrupción del fenómeno del lavinismo en el contexto electoral de 1999 incorporó una primera modificación del dispositivo transicional, consistente en la alteración del equilibrio gobierno-oposición: el éxito de la retórica cosista de la derecha política introdujo en ella la activación de una voluntad de gobierno que condujo a la superación de su cómoda posición de minoría política subsidiada por los enclaves autoritarios y su decisión por disputar el poder político en condiciones de igualdad con la Concertación. De ahí en adelante, la derecha política se instalaba como un actor competitivo progresivamente liberado de las ataduras de la herencia autoritaria, capaz de competir en igualdad de condiciones con el mundo de la centro-izquierda y, a nuestro juicio lo más importante, exitoso en su objetivo de superar (al menos parcialmente) el clivaje democracia-autoritarismo que organizó la primera década post-autoritaria.

En lo que refiere al acuerdo de modernización Lagos-Longueira, su activación representó un hito clave en la modificación de los términos de la lógica consociativa característica del período anterior, toda vez que 1) ubicó a la Concertación en una inédita posición de debilidad ética respecto a la derecha política e 2) incorporó en la escena pública la agenda de probidad y combate a la corrupción. Si en el período anterior la producción de consensos operaba sobre la base de una coalición gobernante que equiparaba su posición institucionalmente precaria con una superioridad ética respecto a una derecha política comprometida con el legado autoritario, la exposición de los reseñados escándalos de probidad forzaba ahora a la Concertación a buscar acuerdos con la oposición para reponer su dañada legitimidad. Y la presta acción opositora, liderada por Pablo Longueira, permitió a la derecha recuperar terreno en cuanto actor con credenciales éticas y políticas equivalente a las de su adversario político.

La respuesta de la Presidenta Bachelet a las movilizaciones estudiantiles del año 2006, por su parte, introdujo un factor hasta entonces inexistente en la política nacional: el despliegue de un discurso vinculado al reconocimiento de la participación social y ciudadana en tanto mecanismo de resolución de conflictos. Si bien las comisiones asesoras presidenciales no constituyeron una medida inédita desde el retorno a la democracia en 1990, en el marco del conflicto estudiantil operaron como mecanismo que, a nuestro juicio, reconocía 1) las limitaciones de las fórmulas elitarias de resolución de conflictos propias del período anterior, 2) el aumento progresivo de la conflictividad social y 3) la necesidad de reformular los mecanismos de interacción entre la élite política y la ciudadanía. 
La política contra-cíclica gestada hacia fines del primer gobierno de Bachelet con el objeto de hacer frente a la crisis económica, por último, expresó la incorporación de un nuevo relato de parte del mundo concertacionista: el relato de la protección estatal ante los riesgos sociales. Centrado durante la década de los noventa en la reconstrucción institucional y la recuperación de la certidumbre democrática, el proyecto concertacionista convivió con el desarrollo de un modelo económico-social que, según lo constataba el referido informe del PNUD de fines de la década de los noventa, comenzaba a generar progresivamente un malestar social larvado frente al cual el dispositivo transicional no ofrecía formas de procesamiento. La respuesta contra-cíclica a la crisis del 2009, expresada ilustrativamente en la activación de la "política de bonos", manifestó una modificación tanto a nivel de discurso como de política pública (con antecedentes provenientes de la administración del Presidente Lagos) que, evidentemente, alteraba los términos de la ortodoxia liberal de los noventa. Sin alterar las bases estructurales del modelo económico-social chileno, en síntesis, el despliegue de la política de protección social constituyó un esfuerzo de conformación de un renovado sentido histórico capaz de hacer frente a nuevos desafíos y tensiones no planteadas en el contexto previo.

Es así como, en definitiva, a lo largo de este artículo hemos querido sostener que la forma en que el campo político-institucional enfrentó las expresiones latentes y manifiestas de malestar social durante el período que media entre los años 1999 y 2009 expresa un proceso de disminución progresiva de la capacidad del dispositivo transicional para dar respuesta a nuevas contingencias no presentes durante la primera década post-dictatorial. Si bien resulta indudable que durante este período el dispositivo transicional se mantuvo vigente, resulta también claro que, desde fines de la década de los noventa, se ingresó según plantea nuestra hipótesis a una nueva fase que, con la crisis sociopolítica del año 2011, marcó el quiebre definitivo del dispositivo transicional.

\section{Bibliografía}

Fuentes impresas

Agamben, Giorgio, “¿Qué es un dispositivo?”, Sociológica, año 26: 73, 249-264.

Aguilera, Carolina, "Participación ciudadana en el gobierno de Bachelet: consejos asesores presidenciales", América Latina Hoy, 46, 2007, 119-143.

Andrés Allamand, El desalojo. Por qué la Concertación debe irse el 2010, Santiago, Editorial Aguilar, 2007.

Baeza-Rodríguez, Cecilia, "Los discursos públicos sobre la gobernabilidad en Chile como relatos de acción pública: un enfoque cognitivista sobre la importación de las ideas", Nuevo mundo. Mundos nuevos. Disponible en:

https://nuevomundo.revues.org/11042.

Barozet, Emanuelle, "Movilización de recursos y redes sociales en los neopopulismos: hipótesis de trabajo para el caso chileno", Revista de ciencia política XXIII: 1, 2003, 39-54.

Bourdieu, Pierre, Campo de poder, campo intelectual, Buenos Aires, Montressor, 2002. 
Cárcamo, Jorge, Codificación Política de la Demanda Estudiantil-Secundaria durante la Administración Gubernamental de Michelle Bachelet (2006-2010), Tesis para optar al grado académico de Magister en Análisis sistémico aplicado a la sociedad, Facultad de ciencias sociales, Universidad de Chile, 2014. Disponible en http://repositorio.uchile.cl/handle/2250/135905. Fecha de consulta: 30 de junio 2017.

Cleuren, Herwin, "Local Democracy and Participation in Post-Authoritarian Chile", European Review of Latin American and Caribbean Studies, 83, 2007.

Contreras, Gonzalo y Patricio Navia, "Diferencias generacionales en la participación electoral en Chile, 1988-2010", Revista de ciencia política, XXXIII: 2, 2013, 39-54.

Cortés Terzi, Antonio, Gobierno de Lagos: ¿Proyecto histórico o ceremonia del adiós?, Avance, 37, 2000. Disponible en: http://www.socialismochileno.org/avance/gobierno-de-lagos-proyecto-hist-ricoo-ceremonia-del-adi-s.html. Fecha de consulta: 30 marzo 2017.

Donoso, Sofía, "Dynamics of Change in Chile: Explaining the Emergence of the 2006 Pingüino Movement", Journal of Latin American Studies, 45: 1, 2013, 1-29. Disponible en: https://doi.org/10.1017/S0022216X12001228.

Franceschet, Susan, "El triunfo de Bachelet y el ascenso político de las mujeres", Nueva sociedad, 202, 2006, 13-22.

French-Davis, Ricardo, "El impacto de la crisis global en América Latina", Nueva sociedad, 224, 2009, 67-85.

Fuentes, Claudio, El pacto. Poder, constitución y prácticas políticas en Chile (1990-2010), Santiago, Ediciones UDP, 2013.

Funk, Robert, "Chile: segundo tiempo”, Revista de ciencia política, 29: 2, 2003, 301-326.

Garretón, Manuel Antonio, Neoliberalismo corregido y progresismo limitado. Los gobiernos de la Concertación en Chile, 1990-2010, Santiago, ARCIS-CLACSO, 2012

Garretón, Manuel Antonio, "La (in)conducción política del segundo gobierno democrático", en Oscar Muñoz y Carolina Stefoni Coordinadores, El período del Presidente Frei Ruiz Tagle, Santiago, Editorial Universitaria, 2003, 52-80.

Garretón, Manuel Antonio, Hacia una nueva era política. Estudio sobre las democratizaciones, Santiago, FCE, 1995.

Hunneus, Carlos, La democracia semisoberana. Chile después de Pinochet, Santiago, Taurus, 2014.

Joignant, Alfredo y Patricio Navia, "De la política de individuos a los hombres de partido", Estudios públicos, 89, Santiago de Chile, 2003, 129-171

Joignant, Alfredo y Menéndez-Carrión Amparo, "De la democracia de los acuerdos a los dilemas de la polis: ¿transición incompleta o ciudadanía pendiente”. En Alfredo Joignant y Amparo Menéndez-Carrión editores, La caja de pandora. El retorno de la transición chilena Joignant, A. y Menéndez-Carrión, A. edits., Santiago, Planeta/Ariel, 1999, 13-48.

Laclau, Ernesto, La Razón populista, Buenos Aires, FCE, 2005.

Laclau, Ernesto y Chantal Mouffe, hegemonía y estrategia socialista. Hacia una radicalización de la democracia; Buenos Aires, FCE, 2004. 
Lechner, Norbert, Los patios interiores de la democracia. Subjetividad y política, FCE, Santiago, 1988.

Lagos, Ricardo, Mi vida. De la infancia a la lucha contra la dictadura. Memorias I, Santiago, Debate, 2013

Mella, Marcelo, "El eclecticismo no resuelto del liderazgo de Ricardo Lagos", Documentos y Aportes en Administración Pública y Gestión Estatal, Santiago, 2010, 10: 14, 113 142

MIDEPLAN, Componentes Centrales de un Sistema de Protección Social Sustentable: El Nuevo Escenario Social en Chile, 2005. Disponible en

\section{http://www.ministeriodesarrollosocial.gob.cl/admin/docdescargas/centrodoc/centrod} oc 241.pdf. Fecha de consulta: 30 de julio 2017.

Morales, Marjorie, "Nueva Gestión Pública en Chile: Orígenes y efectos", Revista de ciencia política, 34: 2, 2014, 417-438.

Morales, Mauricio, "La primera mujer Presidenta de Chile. ¿Qué explicó el triunfo de Michelle Bachelet en las elecciones de 2005-2006", Latin American Research Review, 43: 1, 2008, 7-31.

Moulian, Tomás, Chile actual. Anatomía de un mito, Santiago, LOM, 1997

Muñoz, Víctor, Historia de la UDI. Generaciones y cultura política (1973-2013), Santiago, Ediciones Universidad Alberto Hurtado, 2016

Navarrete, Bernardo y Giovana Gómez, "La reforma administrativa como reacción a una crisis política. El gobierno de Ricardo Lagos (2000-2006)", Revista de estudios politécnicos, VII, 2009.

Navia, Patricio, "Modernización del Estado y Financiamiento de la Política: Una Crisis que se Transformó en Oportunidad. Chile 2003-2004", en Carolina Stefoni editora, Los nuevos escenarios (inter) nacionales, Santiago, FLACSO, 2004.

Navia, Patricio y José Izquierdo, "Cambio y continuidad en la elección de Bachelet", América Latina Hoy, 46, 2007, 75-96.

Navia, Patricio y Alfredo Joignant, Las elecciones presidenciales de 1999: La participación electoral y el nuevo votante chileno, Chile 1999-2000, en Francisco Rojas editor, Nuevo Gobierno: desafíos de la reconciliación, Santiago, FLACSO, 2000.

Ominami, Carlos, Secretos de la Concertación. Recuerdos para el futuro, Santiago, La Tercera ediciones, 2011.

Ottone, Ernesto, El segundo piso. Un ejercicio de memoria, Santiago, Debate, 2016.

Pérez, Mónica y Felipe Gerdtzen, Augusto Pinochet. 503 días atrapado en Londres, Santiago, Catalonia, 2016.

PNUD, Informe de desarrollo humano en Chile. Las paradojas de la modernización. Santiago, PNUD, 1998.

Politzer, Patricia, Bachelet en tierra de hombres, Santiago, Editorial Debate, 2010.

Raczynski, Dagmar, Sistema Chile Solidario y la Política de Protección Social de Chile. Lecciones del pasado y agenda para el futuro, Santiago, CEPAL, 2008.

Sáez, Juan Pablo, "La estrategia argumentativa de Joaquín Lavín y la construcción de un nuevo ethos discursivo en la política chilena", Comunicación y medios, 20. Disponible 
http://www.comunicacionymedios.uchile.cl/index.php/RCM/article/view/15017, 2009

Sáez, José, "La función del voto económico. El caso de España”, El trimestre económico, 69: 276, 2002, 475-512.

Siavelis, Peter, "Enclaves de la transición y democracia chilena", Revista de Ciencia Política, 29: 1, 2009, 3-21.

Silva, Patricio, "Estilos políticos y orientación tecnocrática bajo los gobiernos de Lagos y Bachelet", Revista de sociología, 21, 2007, 79-105.

Tironi, Eugenio, Radiografía de una derrota. O cómo Chile cambió sin que la Concertación se diera cuenta, Uqbar, Santiago, 2010.

Tironi, Eugenio, Felipe Agüero y Eduardo Valenzuela, "Clivajes Políticos En Chile: Perfil Sociológico de Los Electores de Lagos Y Lavín.”, Perspectivas, 5: 11, 2001, 73-87

Tsebelis, George, Veto Players: How Political Institutions Work, Princeton University Press, New Yersey, 2002.

Valdivia, Verónica, La alcaldía de Joaquín Lavín y el lavinismo político en el Chile de los noventa, Disponible en: www.historiapolitica.com, 2012. Fecha de consulta: 30 abril 2017.

Velasco, José, "Nueva imagen electoral en Chile: campañas de Lagos y Lavín", Revista Latinoamericana de Comunicación, 69, 2000, 28-35.

Waissbluth, Mario, "La Reforma del Estado en Chile 1990-2005 De la Confrontación al Consenso", Boletín Electrónico, ESADE, Barcelona PUBLIC, 2006. Disponible en: http://documents.mx/documents/reforma-estado-chile-1990-2005.html. Fecha de consulta: 03 de marzo 2017.

Weeks, Gregory and Silvia Borzutzky, "Michelle Bachelet's Government: The Paradoxes of a Chilean President", Journal of Politics in Latin America, 3, 2012, 97-121.

Fuentes electrónicas

Bachelet, Michelle, "Mensaje de s.e. la presidenta de la República con el que inicia un proyecto de ley que establece incentivos tributarios transitorios, concede un bono extraordinario para las familias de menores ingresos y establece otras medidas de apoyo a la inversión y al empleo", Disponible en http://www.bcn.cl/actualidad_legislativa/plan-economico-crisis-internacional/crisiseconomica, 7 de enero 2009. Fecha de consulta. 30 mayo 2017.

Bachelet, Michelle, "Discurso de la Presidenta Michelle Bachelet", 11 de marzo 2006. Disponible en:http://www.archivochile.com/Chile_actual/Elecciones_2005/Bachelet/11_03_20 06.pdf. Fecha de consulta: 27 junio 2017.

Bachelet, Michelle, Mensaje presidencial 21 de mayo, 2006. Disponible en: http://www.bcn.cl/historiapolitica/mensajes_presidenciales. Fecha de consulta: 27 junio 2017.

Bachelet, Michelle, Programa de Gobierno Michelle Bachelet 2006-2010, 10. Disponible en:

http://www.bcn.cl/obtienearchivo?id=documentos/10221.1/13433/1/2005_programa -MB.pdf. Fecha de consulta: 15 mayo 2017. 
Dittborn, Julio, “Cámara de Diputados República de Chile, Legislatura 356a sesión 121”, 8 enero $2009 . \quad$ Disponible en: http://www.bcn.cl/laborparlamentaria/wsgi/consulta/verDiarioDeSesion.py?id=6409 87. Fecha de consulta: 15 agosto 2017.

Lagos, Ricardo, Discurso del Presidente de la República Ricardo lagos Escobar, 21 de mayo 2003. Disponible en: https://www.bcn.cl/historiapolitica/congreso_nacional/discursos/detalle?tipo=presid entes. Fecha de consulta: 03 de mayo 2017.

Lavín, Joaquín, Franja Electoral segunda vuelta presidencial, 2000. Disponible en: https://www.youtube.com/watch?v=8CgMlobTEeU. Fecha de consulta: 30 mayo 2017.

Lavin, Joaquín y Ricardo Lagos, Debate Presidencial del 2 de noviembre 1999, disponible en: https://www.youtube.com/watch?v=xt5XYWAmGFw. (fecha de consulta: 20 de abril 2017).

Artículos en prensa

Arthur, Bernarda, "Histórico compromiso para detener la corrupción”, El Mercurio, 31 de enero, 2003. Disponible en:

http://diario.elmercurio.com/detalle/index.asp?id=\{6f5bcc59-ff31-44558770a0f36ab2bd0a. Fecha de consulta: 30 mayo 2017.

Campusano, Mauricio, "Lagos y Longueira sellan acuerdo para avanzar en modernización del Estado", El Mercurio, 16 de enero, 2003. Disponible en: http://www.emol.com/noticias/nacional/2003/01/16/102567/lagos-y-longueirasellan-acuerdo-para-avanzar-en-modernizacion-del-estado.html. Fecha de consulta: 30 abril 2017.

González, Paulo y Gloria Faúndez, “El escándalo mejor guardado de la Concertación”, en Revista Qué Pasa, 18 de Octubre 2012.

PNUD, Informe de desarrollo humano en Chile. Las paradojas de la modernización. Santiago, PNUD, 1998.

Schiattino, Roberto, "Directores renuncian en cadena por doble investigación de sobresueldos: Caso Gate desata efecto dominó en Obras Públicas", El Mercurio, viernes 20 de diciembre, 2012 Disponible en: http://diario.elmercurio.com/detalle/index.asp?id $=\{9963881 \mathrm{~d}-8 \mathrm{df9}-462 \mathrm{c}-\mathrm{bb8f}-$ 844585ef5368. Fecha de consulta: 30 enero 2017. 